\title{
Limitations of Electrocardiography for Detecting Left Ventricular Hypertrophy or Concentric Remodeling in Athletes
}

Kristofer Hedman, Kegan J. Moneghetti, David Hsu, Jeffrey W. Christle, Alessandro Patti, Euan Ashley, David Hadley, Francois Haddad and Victor Froelicher

The self-archived postprint version of this journal article is available at Linköping University Institutional Repository (DiVA):

http://urn.kb.se/resolve?urn=urn:nbn:se:liu:diva-163104

N.B.: When citing this work, cite the original publication.

Hedman, K., Moneghetti, K. J., Hsu, D., Christle, J. W., Patti, A., Ashley, E., Hadley, D., Haddad, F., Froelicher, V., (2020), Limitations of Electrocardiography for Detecting Left Ventricular Hypertrophy or Concentric Remodeling in Athletes, American Journal of Medicine, 133(1), 123-132.e8.

https://doi.org/10.1016/j.amjmed.2019.06.028

Original publication available at:

https://doi.org/10.1016/j.amjmed.2019.06.028

Copyright: Elsevier (12 months)

http://www.elsevier.com/

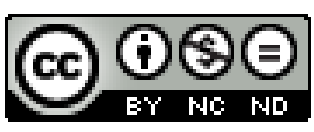




\section{Limitations of Electrocardiography for Detecting Left Ventricular Hypertrophy or Concentric Remodeling in Athletes}

Running head: ECG for detecting left ventricular hypertrophy

Type of manuscript: Clinical Research Study

\section{Authors}

Kristofer Hedman ${ }^{a, b, c}(M D, P h D)$, Kegan J Moneghetti ${ }^{a, d}(M D, P h D)$, David Hsu ${ }^{a, d}$, Jeffrey W Christle ${ }^{a . d}$ (PhD), Alessandro Patti ${ }^{d, e}(M D)$, Euan Ashley ${ }^{a, d}(M D, P h D)$, David Hadley ${ }^{f}(P h D)$, Francois Haddad ${ }^{a, b, d}$ (MD), Victor Froelicher ${ }^{\mathrm{a}, \mathrm{d}}(\mathrm{MD})$

\section{Authors' affiliations}

a. Division of Cardiovascular Medicine, Department of Medicine, Stanford University, Stanford, CA, USA

b. Stanford Cardiovascular Institute, Department of Medicine, Stanford University, Stanford, CA, USA

c. Department of Clinical Physiology and Department of Medical and Health Sciences, Linköping University, Sweden

d. Stanford Sports Cardiology, Stanford University, Stanford, CA, USA.

e. Sport and Exercise Medicine Division, Department of Medicine, University of Padova, Italy

f. Cardiac Insight Inc., Bellevue, WA, USA

\section{Corresponding author:}

Kristofer Hedman

Division of Cardiovascular Medicine, Department of Medicine

Stanford Cardiovascular Institute

300 Pasteur Drive, Stanford

CA 94025, USA

Kristofer.Hedman@liu.se, +1 6507143522 
All authors had access to the data and were active and either drafting or reviewing and revising it for intellectual content.

\section{Possible conflict of interest:}

Dr. Victor Froelicher and Dr. David Hadley are developers and part owners of the ECG system used to acquire the digitized ECG data (Cardea 20/20 ECG System, Cardea Insight Inc., Bellevue, WA, USA). No other potential conflicts of interested are present for any co-author.

\section{Funding for supporting this work:}

Kristofer Hedman received funding through postdoctoral grants from the Fulbright Commission, the Swedish Heart Foundation, the Swedish Society of Medicine and from the County Council of Östergötland, Sweden. In addition, general funding from the Stanford Cardiovascular Institute was used to complete this study.

\section{Key words}

ECG; echocardiography; pre-participation evaluation; athlete's heart; left ventricular mass 


\section{ABSTRACT \\ Background}

Electrocardiography (ECG) is used to screen for left ventricular hypertrophy (LVH), but common ECGLVH criteria have been found less effective in athletes. The purpose of this study was to comprehensively evaluate the value of ECG for identifying athletes with left ventricular hypertrophy and/or a concentric cardiac phenotype.

\section{Methods}

A retrospective analysis of 196 male division 1 college athletes routinely screened with ECG and echocardiography within The Stanford Athletic Cardiovascular Screening Program was performed. Leftventricular mass and volume were determined using echocardiography. Left ventricular hypertrophy was defined as left ventricular mass $>102 \mathrm{~g} / \mathrm{m}^{2}$; a concentric cardiac phenotype as left ventricular mass/volume $(\mathrm{M} / \mathrm{V}) \geq 1.05 \mathrm{~g} / \mathrm{mL}$. Twelve-lead ECGs including high-resolution time intervals and QRS voltages were obtained. 37 previously published ECG-LVH criteria were applied, of which the majority have never been evaluated in athletes. C-statistics, including area under the receiver operating curve (AUC), and likelihood ratios were calculated.

\section{Results}

ECG lead voltages were poorly associated with left ventricular mass $(\mathrm{r}=0.18-0.30)$ and $\mathrm{M} / \mathrm{V}(\mathrm{r}=0.15-$ 0.25). The proportion of athletes with ECG-LVH was $0-74 \%$ across criteria, with sensitivity and specificity ranging between $0-91 \%$ and $27-99.5 \%$, respectively. The average AUC of the criteria in identifying the 11 athletes with left ventricular hypertrophy was 0.57 (95\% CI 0.56-0.59), while the average AUC for identifying the eight athletes with a concentric phenotype was 0.59 (95\% CI 0.56-0.62).

\section{Conclusion}


The diagnostic capacity of all ECG-LVH criteria were inadequate and therefore not clinically useful in screening for left ventricular hypertrophy or a concentric phenotype in athletes. This is probably due to the weak association between left ventricular mass and ECG voltage. 


\section{INTRODUCTION}

Electrocardiography (ECG) is currently recommended as part of the athletic pre-participation screening protocol, ${ }^{1,2}$ and several studies have proven its role for screening for cardiomyopathies and channelopathies. ${ }^{3}$ The role of ECG for identifying left ventricular hypertrophy (LVH) remains more controversial, and the current guidelines for ECG interpretation in athletes consider an isolated finding of increased QRS-voltage a normal finding. ${ }^{2}$ Although scarcely evaluated in athletes, ${ }^{4-6}$ this recommendation is logical considering the low diagnostic accuracy of the most commonly used ECG criteria for detecting left ventricular hypertrophy. ${ }^{7,8}$

Several ECG based criteria have been proposed to assess left ventricular hypertrophy (ECG$\mathrm{LVH}$ ), focusing on either limb voltage, precordial voltage, or their combination. In addition, non-voltage parameters such as QRS-duration have been incorporated into ECG-LVH criteria and point scores as well as an ECG-based equation of left ventricular mass estimation have been developed. Currently, it is unknown how these different criteria compare for the detection of left ventricular hypertrophy in athletes.

Moreover, considering the physiological increase in left ventricular mass frequently reported in athletes, ${ }^{2,9}$ identifying those subjects with a non-proportional increase in left ventricular mass might be of greatest clinical value. ${ }^{10,11}$ This can be quantified as the left ventricular mass to volume ratio (M/V), which previously has been shown to distinguish physiological from pathological left ventricular remodeling in athletes. ${ }^{12,13}$ Whether any available ECG-LVH criteria can identify athletes with increased $\mathrm{M} / \mathrm{V}$ has not been explored.

The main purpose of the current study was to compare 37 voltage and non-voltage ECG criteria for the detection of left ventricular hypertrophy in college athletes, as well as for identifying those athletes with a concentric cardiac phenotype, estimated by $\mathrm{M} / \mathrm{V}$. 


\section{METHODS}

\section{Cohort}

Participants included male college athletes who had a digitized resting ECG and a routine echocardiographic examination as part of their annual pre-participation cardiovascular screening evaluation (PPE) at Stanford University between 2010-2016. Exclusion criteria were (i) abnormal ECG findings as per current guidelines, ${ }^{2}$ (ii) probable electrode misplacement on retrospective ECG evaluation, (iii) inadequate echocardiographic image quality. All participants signed consent forms at the PPE and echocardiographic examination approved by the institutional review board at Stanford University (approval numbers 12245 and 25673, respectively).

\section{ECG examination and interpretation}

Standard 12-lead ECGs were acquired by experienced medical personnel within the Stanford Sports Cardiology PPE program and were read on-site by an experienced sports cardiologist. The ECG tracings were recorded at $25 \mathrm{~mm} / \mathrm{s}$ and obtained with the athlete in the supine position during quiet respiration after a short period of rest. Detailed, digitized ECG data was collected and saved to a database using the Cardea 20/20 ${ }^{\mathrm{TM}}$ Resting ECG Analysis System (Cardea Insight Inc., Bellevue, WA, USA), including time intervals with a precision of $1 \mathrm{~ms}, \mathrm{P}-\mathrm{QRS}-\mathrm{T}$ amplitudes with a precision of $1 \mu \mathrm{V}(1 / 1000 \mathrm{mV})$ and timevoltage area of the P-wave, QRS-complex and ST-T complex. For data analysis, the greatest deflection of either R or r' and of either S and s' were used as R and S wave amplitude, respectively.

For the purpose of this study, all ECGs were re-read manually in November 2018 by the same experienced sports cardiologist, applying the most current guidelines. ${ }^{2}$

\section{ECG criteria}

We applied 37 available ECG criteria with published thresholds for detection of left ventricular hypertrophy. summarized in Figure 1 and detailed in eTable1 in Supplements. This included the current 
criterion for ECG interpretation in athletes, ${ }^{2} 24$ criteria summarized in the current guidelines for ECG interpretation in cardiac chamber hypertrophy, ${ }^{7}$ eight criteria recently evaluated by our group for longterm cardiovascular mortality in a non-athletic population, ${ }^{14}$ and four additional criteria. We categorized each criteria as either of (I) voltage only criteria ( $\mathrm{n}=30)$; (II) criteria including QRS-duration ( $\mathrm{n}=4)$; (III) point score criteria ( $\mathrm{n}=2)$ and (IV) mass equation criterion $(\mathrm{n}=1)$. The voltage only criteria were further sub-categorized as (Ia) limb lead (n=7); (Ib) precordial lead (n=15) or (Ic) limb+precordial lead voltage criteria $(n=8)$. 


\section{Echocardiographic determination of left ventricular mass and $M / V$}

All subjects had an echocardiographic examination within 30 days from the ECG recording, of which $81 \%$ was performed the same day. Echocardiography was performed with subjects in the lateral decubitus position using a commercially available system (iE33; Philips Medical Imaging, Andover, MA, USA) with images analyzed on Xcelera workstations. The echocardiographic protocol included 2-D and color Doppler in parasternal and apical views. Left ventricular mass (LVM) and volume were calculated using the area-length method in end-diastole from short-axis images and left ventricular length was measured in the apical 4-chamber view (eFigure 1 in Supplement). Mass to volume ratio was derived by dividing left ventricular mass by left ventricular volume. Left ventricular mass was indexed by body surface area (BSA; LVM[BSA]) as well as by allometrically scaled body surface area and height (LVM[BSA $\left.{ }^{1.5}\right]$ and LVM[height $\left.\left.{ }^{2.7}\right]\right)$. The presence of left ventricular hypertrophy per echocardiography was determined using current echocardiographic guidelines ${ }^{15}$; LVM[BSA] $>102 \mathrm{~g} / \mathrm{m}^{2}$. A concentric cardiac phenotype was defined as a $\mathrm{M} / \mathrm{V}$ in the upper $95^{\text {th }}$ percentile of the cohort.

\section{Statistical analyses}

SPSS software, v25.0 (IBM Corp, Armonk, NY, USA) was used for database management and statistical analysis. R Studio v1.1.456 (R Studio Inc., Vienna, Austria) was used to calculate the numeric sums of each combined criterion and to determine which criteria each athlete fulfilled. These scripts are included in eMethods. Continuous data were expressed as mean $\pm \mathrm{SD}$, categorical data as number of observations and frequency. We evaluated differences between groups with Student's t-test for continuous variables and $\mathrm{Chi}^{2}$ test for categorical variables and $\mathrm{P}$-values $<0.05$ were considered statistically significant. The physiological association between single lead voltage as well as summed voltages within each criterion and indexed and unindexed left ventricular mass and $\mathrm{M} / \mathrm{V}$ were explored using bivariate correlation analysis, where negative deflections ( $\mathrm{Q}$ and $\mathrm{S}$ waves) were transferred to their absolute (positive) values. We calculated the odds ratios for having left ventricular hypertrophy by echocardiography and selected 
ECG criteria, respectively, based on anthropometric and demographic variables using binary logistic regression.

Area under the receiving operating curve (AUC) with 95\% confidence interval (CI) was calculated for each ECG criterion with its corresponding, suggested cut-off value, using (i) echocardiographic left ventricular hypertrophy as per guidelines, (ii) $\mathrm{M} / \mathrm{V}$ in upper $95^{\text {th }}$ percentile or (i) and (ii) in combination as outcome variable, respectively. An AUC with a 95\% CI overlapping 0.5 was considered non-discriminatory. The methodology and calculations of each diagnostic metric is detailed in eTable 2, assuming a pre-test probability equal to the prevalence of each entity. 


\section{RESULTS}

196 male athletes were included after excluding two subjects with a pathological ECG (one with anterior pathological Q-wave, one with pathological lateral T-wave inversion), three subjects with lead misplacement and four subjects where echocardiographic images did not allow reliable left ventricular mass estimation.

\section{Left ventricular mass and $M / V$ by echocardiography}

LVM[BSA] and M/V were normally distributed (figure $2 \mathrm{a}+\mathrm{b}$ ), with average values of $81 \pm 12 \mathrm{~g} / \mathrm{m}^{2}$ and $0.87 \pm 0.10 \mathrm{~g} / \mathrm{mL}$, respectively. The upper $95^{\text {th }}$ percentile of LVM[BSA] was $102 \mathrm{~g} / \mathrm{m}^{2}$, identical to the threshold in echocardiographic guidelines for defining left ventricular hypertrophy. ${ }^{15}$ and 11 athletes displayed echocardiographic left ventricular hypertrophy. Four of the eight athletes in the upper $95^{\text {th }}$ percentile for M/V (1.05 g/mL) also had left ventricular hypertrophy (figure $2 \mathrm{c}+\mathrm{d}$ ).

\section{Proportion of athletes with positive ECGs}

There was a large difference between ECG-LVH criteria in the number of athletes with a positive ECG, ranging from 0 to $74 \%$ (figure 3a). In particular, with the original version of the Sum of 12 leads and Sum of 12 -leads-product criteria, $68 \%$ and $74 \%$ of athletes, respectively, had a positive ECG.

Forty-nine (25\%) athletes fulfilled the ECG-LVH criterion in current athletic guidelines (S V1 + $\mathrm{R} \mathrm{V5/V6>35} \mathrm{mm).}{ }^{2}$ As seen in table 1, these subjects were on average leaner (body mass index $25 \pm 4 \mathrm{vs.}$ $\left.28 \pm 5 \mathrm{~kg} / \mathrm{m}^{2}, \mathrm{p}<0.001\right)$ and included a larger proportion of Afro-American athletes (47\% vs. $27 \%$, $\mathrm{p}<0.001)$ and basketball players $(24 \%$ vs. $3 \%, \mathrm{p}<0.001)$.

By sports, $18 \%$ of American football, $25 \%$ of volleyball and $75 \%$ of basketball players fulfilled the guideline criterion. Accordingly, the odds ratio for being positive for ECG-LVH as per current guidelines was 4.3 (95\% CI 1.0-18.2) for basketball players and $0.3(0.1-1.0)$ for subjects with a body mass index $>30 \mathrm{~kg} / \mathrm{m}^{2}$ in a multivariable logistic regression model (eTable 3). In contrast, having left 
ventricular hypertrophy per echocardiography (i.e. an LVM[BSA] $>102 \mathrm{~g} / \mathrm{m}^{2}$ ) was not associated with ECG-LVH per current guidelines $(\beta=2.7,95 \%$ CI $0.8-9.2, p=0.12)$.

\section{Association between left ventricular mass and ECG voltage}

Unindexed left ventricular mass was correlated with R-wave amplitude in aVL, I, V5 and V6 (Pearson $\mathrm{r}=0.18-0.30$, eTable 4). Indexing left ventricular mass by body surface area or allometrically with either BSA $^{1.5}$ or height ${ }^{2.7}$ had little impact on the strength of these correlations.

In general, the correlations were similarly weak between indexed and unindexed left ventricular mass, $\mathrm{M} / \mathrm{V}$ and ECG measures when the latter were combined as within different criteria (eTable 5). The only exception was the Framingham adjusted Cornell criteria ${ }^{16}$, accounting for age, sex and body mass index, where the correlation to unindexed left ventricular mass was nominally stronger $(r=0.50, \mathrm{p}<0.001)$.

\section{Diagnostic ability of ECG criteria for detecting left ventricular hypertrophy or/and a high M/V}

Left ventricular hypertrophy

As seen in figure $3 \mathrm{~b}$, the greatest AUC of any criterion for detecting the 11 subjects with left ventricular hypertrophy was 0.69 (95\% CI 0.52-0.86) for the combined Sokolow-Lyon criteria; the only criterion with a AUC 95\% CI not overlapping 0.50. The average AUC of all criteria was 0.57 (95\% CI 0.56-0.59). There was a wide range in both sensitivity and specificity among criteria for detecting left ventricular hypertrophy (Figure 4 and eTable 5). The highest positive likelihood ratio for any criterion was 8.4 for having an S-wave in V1 $>23 \mathrm{~mm}$, resulting in a post-test probability of having left ventricular hypertrophy of $33 \%$ (eFigure 3).

Mass to volume ratio $(M / V)$

The diagnostic ability of the ECG criteria to identify the eight athletes with a M/V in the upper $95^{\text {th }}$ percentile (i.e. $\geq 1.05 \mathrm{~g} / \mathrm{mL}$ ) is detailed in eTable 6 and Figure 4. The average AUC was 0.59 (95\% CI 0.56-0.62) and four criteria had an AUC $>0.70$, all with a 95\% CI not-overlapping 0.50; Romhilt-Estes point score (AUC 0.74); Perugia point score (AUC 0.71); modified sum of 12 leads (AUC 0.74); 
modified sum of 12 leads-product (AUC 0.72 ). No criterion had a post-test probability $>20 \%$ if ECGLVH positive (eFigure 3).

The difference in AUC for each criterion's ability to identify left ventricular hypertrophy and a high $\mathrm{M} / \mathrm{V}$, respectively is contrasted in eFigure 4. In particular, the Romhilt-Estes score had higher AUC for identifying subjects with a high M/V than those with left ventricular hypertrophy (M/V AUC: 0.74 vs. left ventricular hypertrophy AUC: 0.56).

The combination of left ventricular hypertrophy and a concentric phenotype

The ability of the ECG criteria to identify the four subjects with both echocardiographic left ventricular hypertrophy and high $\mathrm{M} / \mathrm{V}$ was generally superior to identifying left ventricular hypertrophy or high $\mathrm{M} / \mathrm{V}$ alone. Three criteria, all precordial, had an AUC $>0.75$; $\max$ of $(\mathrm{R}+\mathrm{S})$ in any precordial lead $>35 \mathrm{~mm}$ (AUC 0.87, 95\% CI 0.78-0.95); S V1 + R V5 >35 mm (AUC 0.76, 95\% CI 0.51-1.00) and S V1 + R V5/V6 $>35 \mathrm{~mm}$ (AUC 0.76, 95\% CI 0.51-1.00). Having an R $+\mathrm{S}$ wave $>35 \mathrm{~mm}$ in any precordial lead identified all four athletes with a specificity of $73 \%$. The positive likelihood ratio of this criteria was 27.8 , while the low prevalence $(2 \%)$ constrained the post-test probability of having a combination of left ventricular hypertrophy and high $\mathrm{M} / \mathrm{V}$ at $37 \%$. 


\section{DISCUSSION}

This study demonstrates that QRS-amplitudes on surface ECG can not be used as a marker of left ventricular mass in male athletes, and none of the 37 ECG-LVH criteria evaluated are clinically useful for discriminating athletes with abnormally high left ventricular mass or with a concentric cardiac phenotype. A few precordial lead ECG criteria performed reasonably well in identifying athletes with a combination of left ventricular hypertrophy and high M/V (i.e. concentric hypertrophy), which is a novel albeit exploratory finding that could be of substantial clinical value and invites further studies.

The cardiac phenotype of athletes ('athlete's heart') has been extensively studied during the past three decades. ${ }^{9,17,18}$ Our understanding of the physiological cardiac adaptations occurring with high-level exercise training has increased in parallel with the evolution of cardiac imaging techniques, ${ }^{19}$ and largescale athletic screening programs on a national level. ${ }^{18,20}$ The purpose of the PPE of athletes is primarily to identify athletes with underlying heart disease in order to prevent sudden cardiac death. ${ }^{1,2}$ Cardiac imaging is not however, part of the routine PPE for a majority of athletes and the decision on the need of further follow-up investigations relies on the personal and family history, physical examination and - in most cases - a resting 12-lead ECG. ${ }^{1}$ International efforts have been made to improve the accuracy of this process, in particular for the interpretation of the ECG in athletes. ${ }^{2,21}$ Thus, a correct understanding of the potential and limitations of the ECG to detect structural and electrical abnormalities in athletes are essential for every physician involved in the clinical evaluation of this group of subjects.

Left ventricular hypertrophy imposes a certain clinical dilemma, as increased left ventricular mass is the hallmark of 'athlete's heart' while also being associated with hypertrophic cardiomyopathy, the most frequent inherited cardiac disease found in athletes. ${ }^{22}$ Accordingly, the current guidelines for ECG interpretation in athletes state that fulfillment of a traditional QRS-voltage criterion for ECG-LVH should not by itself merit for further investigation. ${ }^{2}$ As only a few ECG criteria have previously been evaluated in athletes, ${ }^{4-6,23}$ and considering the addition of more recently proposed ECG-LVH criteria, ${ }^{14,24,}$ ${ }^{25}$ we hypothesized that there could be criteria more suitable to use in the PPE setting. However, our 
results clearly show that neither of the voltage, voltage + non-voltage or non-voltage criteria evaluated are useful in identifying subjects with abnormally high left ventricular mass in this group of subjects. The only criterion with an AUC not overlapping 0.50 was the combined Sokolow-Lyon criterion. Although many criteria had a specificity of $\geq 90 \%$, the sensitivity was in most cases $<50 \%$, which is similar to previous evaluations in athletes ${ }^{4,5}$ army recruits $^{26}$ as well as in hypertensive heart disease with left ventricular hypertrophy. ${ }^{24,27}$ Due to the low prevalence (5.6\%) of left ventricular hypertrophy in the cohort, the post-test probabilities for all ECG-LVH criterion were low.

The poor diagnostic ability of the ECG-LVH criteria were not surprising considering the lack of strong correlations between QRS voltage and left ventricular mass. Four single lead QRS-amplitudes (aVL, I, V5, V6), all reflecting the depolarization of the lateral heart wall, correlated weakly to left ventricular mass. Indexing left ventricular mass by allometrically scaled body surface area or height, or body surface area per ratio standard had little impact on the magnitude of the correlation coefficients, nor did summarizing voltages from several leads. This indicates that the heart mass, approximated by left ventricular mass, has little impact on the surface ECG voltage in male athletes and that this can not be explained primarily by inter-individual differences in body surface area or height. Of note, the only criterion where the correlation of voltage sums exceeded a magnitude of $r>0.40$ was the Framingham Adjusted Cornell criteria, which adjust for body mass index and age as continuous variables as well as provides sex specific thresholds. It is possible that factors associated with a high body mass index may influence the diagnostic ability to detect left ventricular hypertrophy in athletes, as previously reported in obese patients with hypertension. ${ }^{28}$ This could reflect an insulating effect of adipose tissue, epicardial and pericardial fat depositions, or increased distance from the heart to chest electrodes. ${ }^{7}$

Ultimately, the purpose of any ECG-LVH criteria used at the PPE setting would be to identify athletes with underlying cardiac pathology or high risk thereof. ${ }^{1,2}$ The threshold in current echocardiographic guidelines for defining left ventricular hypertrophy in a general population is an LVM[BSA] of $>102 \mathrm{~g} / \mathrm{m}^{2},{ }^{15}$ which corresponded to the upper $95^{\text {th }}$ percentile in the current cohort. 
Considering the range in physiological cardiac remodeling reported in athletes, ${ }^{11}$ this might not represent an optimal threshold to identify athletes with a higher risk of pathology. Therefore, we also evaluated the ECG-criteria in their ability in identifying subjects with a more concentric cardiac phenotype, which has been shown to distinguish physiological from pathological remodeling in athletes ${ }^{12,13}$ and to be associated with later development of cardiac functional impairment in hypertensive patients. ${ }^{29}$ In addition, we recently found $\mathrm{M} / \mathrm{V}$ to be positively, and independently associated with higher systolic blood pressure in athletes, ${ }^{30}$ indicating a clinical relevance and possible underlying mechanism for the concentric remodeling in this group. Several of the ECG-LVH criteria performed slightly better in detecting subjects with a high $\mathrm{M} / \mathrm{V}$ ratio than those with isolated left ventricular hypertrophy. which to our knowledge never has been evaluated previously. In particular, the Romhilt-Estes point score (incorporating QRSvoltage, ST-T strain pattern, ventricular activation time, left atrial abnormalities, QRS-axis and -duration) had an AUC of 0.74 for identifying high $\mathrm{M} / \mathrm{V}$ as compared to 0.56 for left ventricular hypertrophy. Intriguingly, all four athletes with a combination of left ventricular hypertrophy and high M/V ratio (i.e. concentric hypertrophy) fulfilled the criterion of having an $\mathrm{R}+\mathrm{S}$-wave $>35 \mathrm{~mm}$ in any precordial lead, with a specificity of $73 \%$ and an AUC of 0.87 . Clinically, this group of subjects is the most important to identify, as concentric hypertrophy more often is associated with pathological remodeling in athletes, than left ventricular hypertrophy alone. This finding prompts for validation in larger cohorts.

\section{Limitations}

First, due to the low number of females with echocardiographic examinations, we only included male athletes because of established differences in cardiac remodeling between sexes. Our results are limited to male athletes at a college age. Younger athletes might present with more juvenile ECG patterns and older athletes may have underlying cardiovascular disease and hypertension, possibly modifying the LVM-ECG-voltage relationship. Second, we used echocardiography as the method for determining left ventricular mass in favor of cardiac magnetic resonance imaging. Although this method may be increasingly utilized in a PPE setting in the future, sports physicians currently rely on echocardiography 
for the evaluation of athletes, with echocardiographic normative values being more established. Third, including subjects with known pathological remodeling, such as hypertrophic cardiomyopathy could have yielded additional insights into the difference between physiological and pathological remodeling. However, this group of subjects often present with electrophysiological alterations in addition to remodeling and have lower than expected $\mathrm{R}$ and $\mathrm{S}$ wave amplitudes because of replacement of myocytes with fibrosis and fat deposits.

\section{Conclusion}

The correlations between left ventricular mass and ECG voltage are weak in male athletes, and none of the 37 evaluated ECG criteria are able to identify athletes with left ventricular hypertrophy or a high M/V ratio with sufficient discriminatory capacity (AUC) to be useful in evaluating athletes.

\section{ACKNOWLEDGEMENTS}

The authors wish to acknowledge the personnel and volunteers at Stanford Clinical and Echocardiographic Pre-Participation Evaluation program for their great efforts. 


\section{REFERENCES}

1. Mont L, Pelliccia A, Sharma S, et al. Pre-participation cardiovascular evaluation for athletic participants to prevent sudden death: Position paper from the EHRA and the EACPR, branches of the ESC. Endorsed by APHRS, HRS, and SOLAECE. Eur J Prev Cardiol. 2017;24:41-69.

2. Sharma S, Drezner JA, Baggish A, et al. International recommendations for electrocardiographic interpretation in athletes. Eur Heart J. 2018;39:1466-1480.

3. Harmon KG, Zigman M, Drezner JA. The effectiveness of screening history, physical exam, and ECG to detect potentially lethal cardiac disorders in athletes: a systematic review/meta-analysis. J Electrocardiol. 2015;48:329-338.

4. Douglas PS, O'Toole ML, Hiller WD, Hackney K, Reichek N. Electrocardiographic diagnosis of exercise-induced left ventricular hypertrophy. Am Heart J. 1988;116:784-790.

5. Speranza G, Magaudda L, de Gregorio C. Adult ECG criteria for left ventricular hypertrophy in young competitive athletes. Int J Sports Med. 2014;35:253-258.

6. Dimitros E, Koutlianos N, Anifanti M, Pagourelias E, Koudini E, Deligiannis A. Comparative study of ECG and echocardiographic parameters indicative of cardiac hypertrophy in athletes. Sport Sci Health. 2012;8:101-107.

7. Hancock EW, Deal BJ, Mirvis DM, et al. Electrocardiogram changes associated with cardiac chamber hypertrophy: a scientific statement from the American Heart Association Electrocardiography and Arrhythmias Committee, Council on Clinical Cardiology; the American College of Cardiology Foundation; and the Heart Rhythm Society. Endorsed by the International Society for Computerized Electrocardiology. J Am Coll Cardiol. 2009;53:992-1002.

8. Levy D, Labib SB, Anderson KM, Christiansen JC, Kannel WB, Castelli WP. Determinants of sensitivity and specificity of electrocardiographic criteria for left ventricular hypertrophy. Circulation. 1990;81:815-820.

9. Utomi V, Oxborough D, Whyte GP, et al. Systematic review and meta-analysis of training mode, imaging modality and body size influences on the morphology and function of the male athlete's heart. Heart. 2013;99:1727-1733.

10. De Innocentiis C, Ricci F, Khanji MY, et al. Athlete's Heart: Diagnostic Challenges and Future Perspectives. Sports Med. 2018;48:2463-2477.

11. Utomi V, Oxborough D, Ashley E, et al. Predominance of normal left ventricular geometry in the male 'athlete's heart'. Heart. 2014;100:1264-1271.

12. Petersen SE, Selvanayagam JB, Francis JM, et al. Differentiation of athlete's heart from pathological forms of cardiac hypertrophy by means of geometric indices derived from cardiovascular magnetic resonance. J Cardiovasc Magn Reson. 2005;7:551-558.

13. Luijkx T, Cramer MJ, Buckens CF, et al. Unravelling the grey zone: cardiac MRI volume to wall mass ratio to differentiate hypertrophic cardiomyopathy and the athlete's heart. Br J Sports Med. 2015;49:1404-1409.

14. Ha LD, Elbadawi A, Froelicher VF. Limited Relationship of Voltage Criteria for Electrocardiogram Left Ventricular Hypertrophy to Cardiovascular Mortality. Am J Med. 2018;131:101 e101-101 e108.

15. Lang RM, Badano LP, Mor-Avi V, et al. Recommendations for cardiac chamber quantification by echocardiography in adults: an update from the American Society of Echocardiography and the European Association of Cardiovascular Imaging. Eur Heart J Cardiovasc Imaging. 2015;16:233270. 
16. Norman JE, Jr., Levy D, Campbell G, Bailey JJ. Improved detection of echocardiographic left ventricular hypertrophy using a new electrocardiographic algorithm. J Am Coll Cardiol. 1993;21:1680-1686.

17. Spirito P, Pelliccia A, Proschan MA, et al. Morphology of the "athlete's heart" assessed by echocardiography in 947 elite athletes representing 27 sports. Am J Cardiol. 1994;74:802-806.

18. Pelliccia A, Maron BJ, Spataro A, Proschan MA, Spirito P. The upper limit of physiologic cardiac hypertrophy in highly trained elite athletes. N Engl J Med. 1991;324:295-301.

19. Pelliccia A, Caselli S, Sharma S, et al. European Association of Preventive Cardiology (EAPC) and European Association of Cardiovascular Imaging (EACVI) joint position statement: recommendations for the indication and interpretation of cardiovascular imaging in the evaluation of the athlete's heart. Eur Heart J. 2018;39:1949-1969.

20. Malhotra A, Dhutia H, Finocchiaro G, et al. Outcomes of Cardiac Screening in Adolescent Soccer Players. N Engl J Med. 2018;379:524-534.

21. Drezner JA, Ackerman MJ, Anderson J, et al. Electrocardiographic interpretation in athletes: the 'Seattle criteria'. Br J Sports Med. 2013;47:122-124.

22. Harmon KG, Drezner JA, Wilson MG, Sharma S. Incidence of sudden cardiac death in athletes: a state-of-the-art review. Heart. 2014;100:1227-1234.

23. Samesima N, Azevedo LF, De Matos L, Echenique LS, Negrao CE, Pastore CA. Comparison of Electrocardiographic Criteria for Identifying Left Ventricular Hypertrophy in Athletes from Different Sports Modalities. Clinics (Sao Paulo). 2017;72:343-350.

24. Peguero JG, Lo Presti S, Perez J, Issa O, Brenes JC, Tolentino A. Electrocardiographic Criteria for the Diagnosis of Left Ventricular Hypertrophy. J Am Coll Cardiol. 2017;69:1694-1703.

25. Carlsson MB, Tragardh $\mathrm{E}$, Engblom $\mathrm{H}$, et al. Left ventricular mass by 12 -lead electrocardiogram in healthy subjects: comparison to cardiac magnetic resonance imaging. J Electrocardiol. 2006;39:67-72.

26. Sohaib SM, Payne JR, Shukla R, World M, Pennell DJ, Montgomery HE. Electrocardiographic (ECG) criteria for determining left ventricular mass in young healthy men; data from the LARGE Heart study. J Cardiovasc Magn Reson. 2009;11:2.

27. Pewsner D, Juni P, Egger M, Battaglia M, Sundstrom J, Bachmann LM. Accuracy of electrocardiography in diagnosis of left ventricular hypertrophy in arterial hypertension: systematic review. BMJ. 2007;335:711.

28. Abergel E, Tase M, Menard J, Chatellier G. Influence of obesity on the diagnostic value of electrocardiographic criteria for detecting left ventricular hypertrophy. Am J Cardiol. 1996;77:739-744.

29. Drazner MH. The progression of hypertensive heart disease. Circulation. 2011;123:327-334.

30. Hedman K, Moneghetti KJ, Christle JW, et al. Blood pressure in athletic preparticipation evaluation and the implication for cardiac remodelling. Heart. 2019. 


\section{FIGURES}

All figures also submitted as separate files in their raw, line-art format (.EPS). 


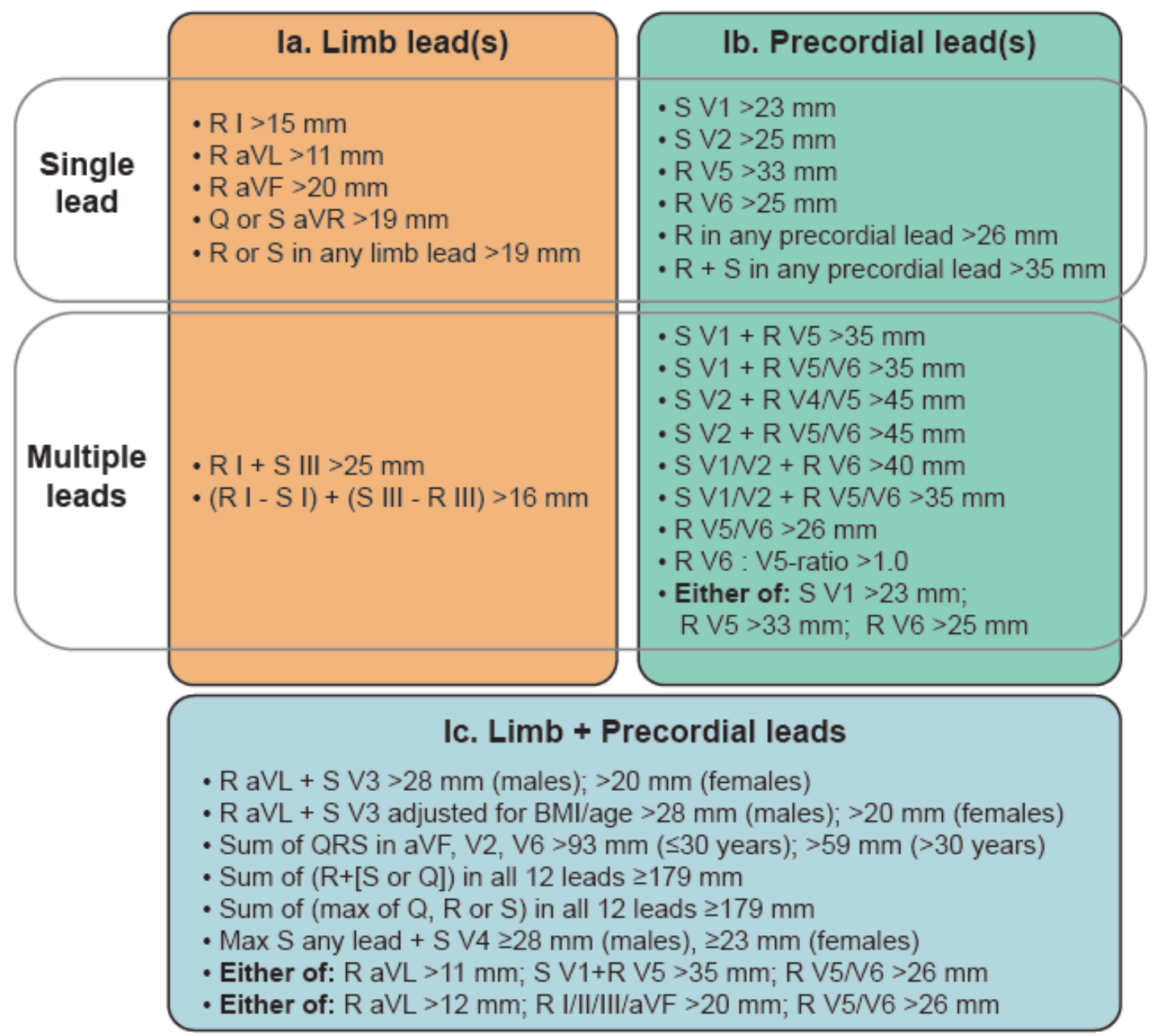

\section{Including QRS-duration}

- QRS-duration $>114 \mathrm{~ms}$ (males); $>97 \mathrm{~ms}$ (females)

- $(\mathrm{R}$ aVL + S V3) * QRS-dur, $\geq 2436 \mathrm{~mm} / \mathrm{ms}$

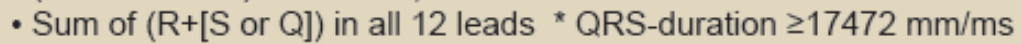

- Sum of ( $\max$ of $Q, R$ or $S$ ) in all 12 leads * $Q R S$-duration $\geq 17472 \mathrm{~mm} / \mathrm{ms}$

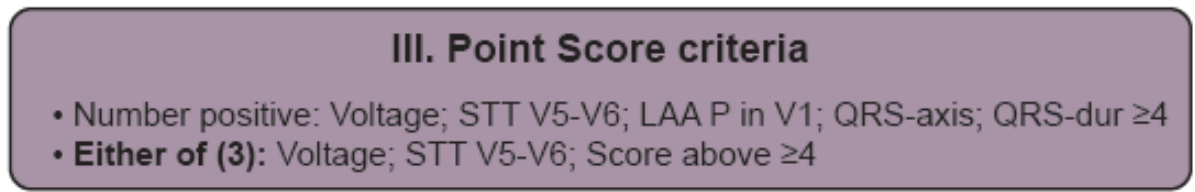

\section{LV mass Equation}

- Rautaharju LV mass Equation

Figure 1. (Two-column figure)

Summary of the 37 different ECG criteria for detecting left ventricular hypertrophy applied in

the 196 male athletes of the current report. For details and references, see eTable 1. 


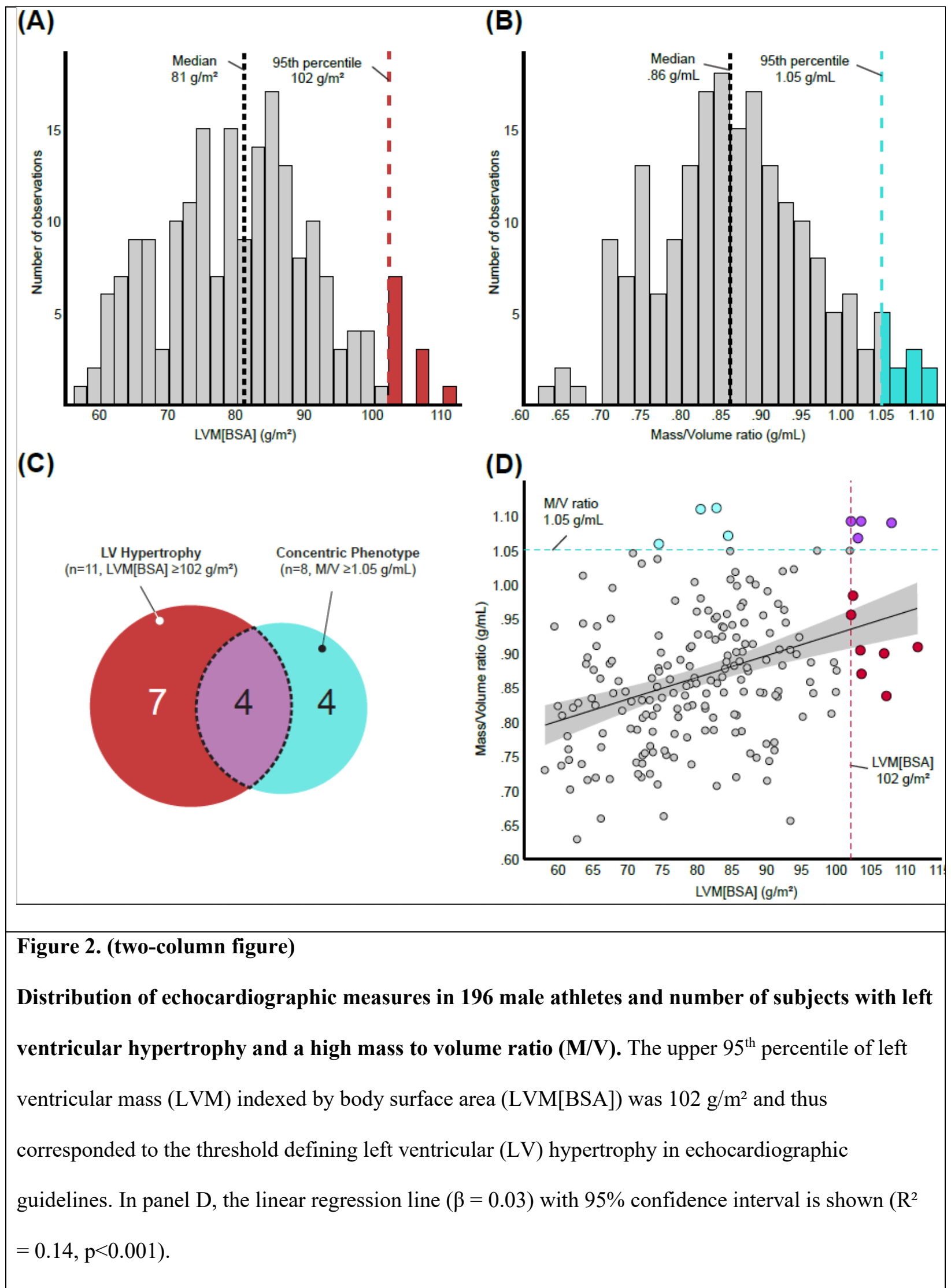




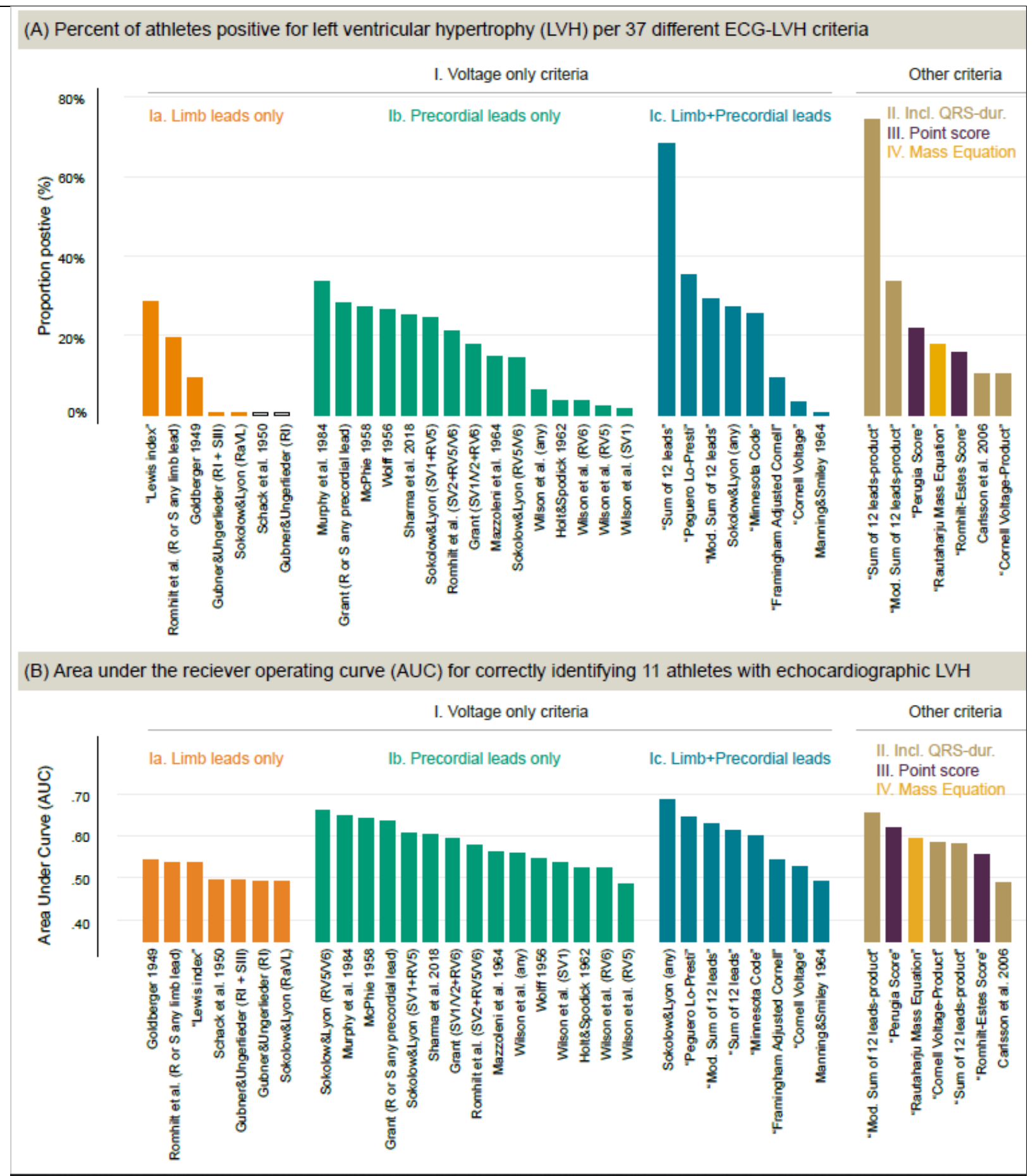

Figure 3. (two-column figure)

Proportion of the 196 male athletes with ECG-LVH using 37 different criteria (A) and the diagnostic characteristics for each criterion (B). The criteria are grouped by category as defined in 
figure 1 and text. For detailed explanation of each criterion with the respective threshold and reference, readers are referred to eTable 1. 


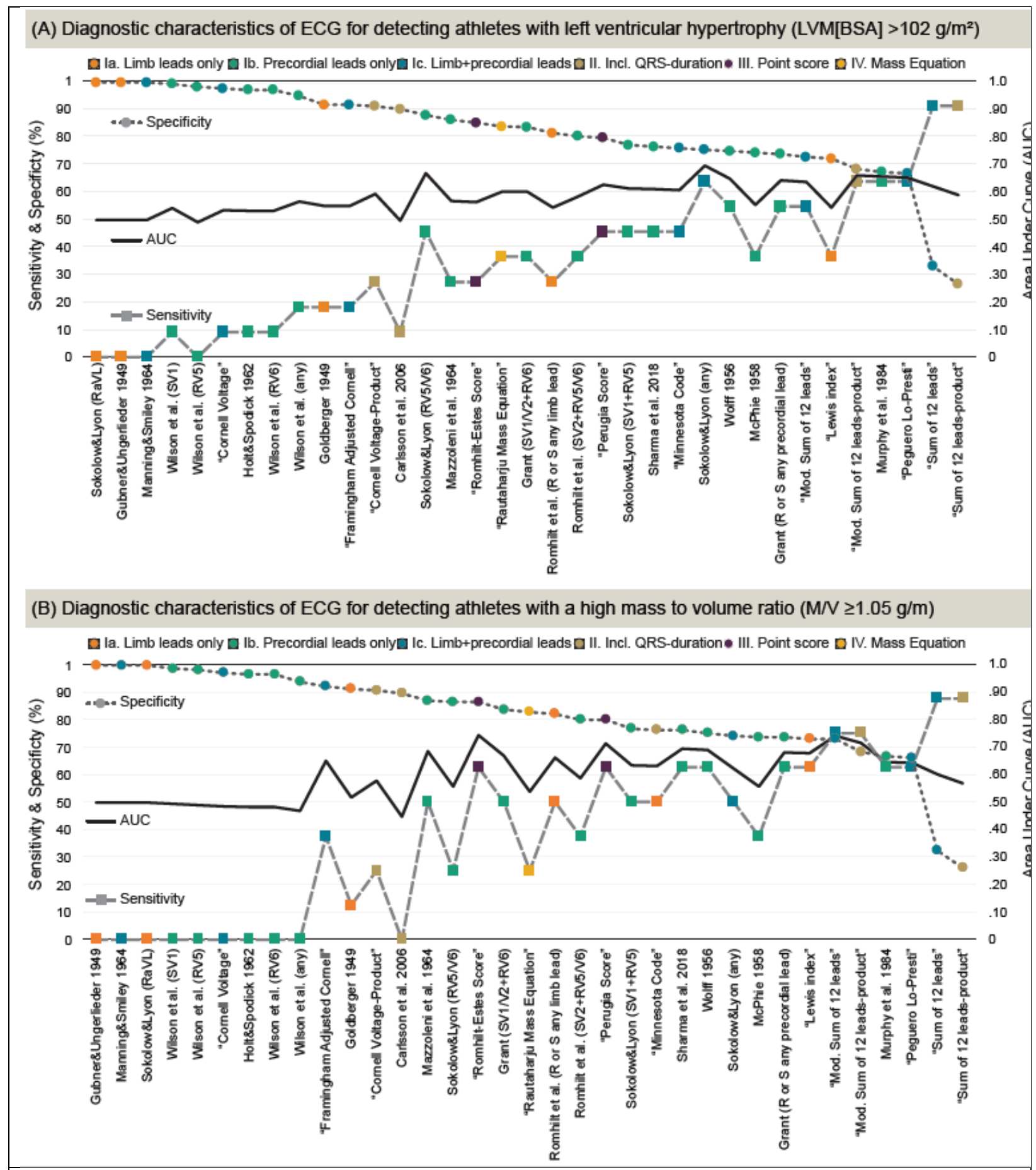

Figure 4. (two-column figure)

Diagnostic characteristics of different ECG-LVH criteria for correctly identifying the 11 athletes with left ventricular hypertrophy (A) and the 8 athletes with a concentric cardiac phenotype (B). 
Sensitivity and specificity are noted on left y-axis and area under the receiving operator curve (AUC) on the right $\mathrm{y}$-axis. and AUC for each criterion, sorted descending from left to right by specificity. 


\section{Supplementary material}

Hedman et al.

“Limitations of Electrocardiography for Detecting Left Ventricular Hypertrophy or Concentric Remodeling in Athletes". 


\begin{tabular}{|c|c|c|c|}
\hline Lead(s) & Threshold/Cut-off & Reference $(\mathbf{s})^{a}$ & Also known as \\
\hline la. Limb lead voltage on & & & \\
\hline Single lead $(n=5)$ & & & \\
\hline R I & $>15 \mathrm{~mm}$ & Gubner \& Ungerlieder, $1943 .{ }^{1}$ & \\
\hline $\mathrm{R}$ aVL & $>11 \mathrm{~mm}$ & Sokolow \& Lyon, 1949.2 & \\
\hline $\mathrm{R}$ aVF & $>20 \mathrm{~mm}$ & Goldberger, $1949 .^{3}$ & \\
\hline Q or $S$ aVR & $>19 \mathrm{~mm}$ & Schack et al. $1950 .{ }^{4}$ & \\
\hline $\mathrm{R}$ or $\mathrm{S}$ in any limb lead & $>19 \mathrm{~mm}$ & Romhilt et al. $1969 .^{5}$ & \\
\hline Multiple leads $(n=2)$ & & & \\
\hline$(R I-S I)+(S I I I-R ~ I I I)$ & $>16 \mathrm{~mm}$ & Lewis, $1914{ }^{6}$ & Lewis index \\
\hline $\mathrm{RI}+\mathrm{SIII}$ & $>25 \mathrm{~mm}$ & Gubner \& Ungerlieder, $1943 .^{1}$ & \\
\hline Ib. Precordial lead voltac & nly & & \\
\hline Single lead $(n=6)$ & & & \\
\hline S V1 & $>23 \mathrm{~mm}$ & Wilson et al. $1944 .^{7}$ & \\
\hline S V2 & $>25 \mathrm{~mm}$ & Mazzoleni et al. $1964 .^{8}$ & \\
\hline R V5 & $>33 \mathrm{~mm}$ & Wilson et al. $1944 .^{7}$ & \\
\hline R V6 & $>25 \mathrm{~mm}$ & Wilson et al. $1944 .^{7}$ & \\
\hline$R+S$ any precordial lead & $>35 \mathrm{~mm}$ & Grant, 1957.9 & \\
\hline $\mathrm{R}$ any precordial lead & $>26 \mathrm{~mm}$ & McPhie, $1958 .{ }^{10}$ & \\
\hline Multiple leads (n=9) & & & \\
\hline S V1 + R V5 & $>35 \mathrm{~mm}$ & Sokolow \& Lyon, $1949 .^{2}$ & \\
\hline & & & $\begin{array}{l}\text { The International } \\
\text { Criteria for ECG }\end{array}$ \\
\hline S V1 + R V5/V6 & $>35 \mathrm{~mm}$ & Sharma et al. $2018 .{ }^{11}$ & $\begin{array}{l}\text { Interpretation in } \\
\text { Athletes }\end{array}$ \\
\hline $\mathrm{S} V 2+\mathrm{R} V 4 / \mathrm{V} 5$ & $>45 \mathrm{~mm}$ & Wolff, $1956 . .^{12}$ & \\
\hline $\mathrm{S} V 2+\mathrm{R} V 5 / \mathrm{V} 6$ & $>45 \mathrm{~mm}$ & Romhilt et al. $1969 .{ }^{5}$ & \\
\hline S V1/V2 + R V5/V6 & $>40 \mathrm{~mm}$ & Murphy et al. $1984 .^{13}$ & \\
\hline S V1/V2 + R V6 & $>40 \mathrm{~mm}$ & Grant, $1957 . .^{9}$ & \\
\hline R V5/V6 & $\begin{array}{l}>26 \mathrm{~mm} \\
\text { Either of: SV1 >23 }\end{array}$ & Sokolow \& Lyon, $1949 .^{2}$ & \\
\hline S V1, RV5, R V6 & $\begin{array}{l}\mathrm{mm}, \mathrm{RV} 5>33 \mathrm{~mm} \\
\mathrm{RV} 6>25 \mathrm{~mm}\end{array}$ & Wilson et al. $1944 .^{7}$ & \\
\hline R V6 : R V5 (ratio) & $>1.0$ & Holt \& Spodick, $1962 .{ }^{14}$ & \\
\hline
\end{tabular}

\section{Ic. Limb and precordial leads $(n=8)$}

\begin{tabular}{|c|c|c|c|}
\hline SV1+RV5, RV5/V6, RaVL & $\begin{array}{l}\text { Either of: SV1+RV5 } \\
>35 \mathrm{~mm}, \mathrm{RV} 5 / \mathrm{V} 6 \\
>26 \mathrm{~mm}, \mathrm{RaVL}>11 \\
\mathrm{~mm}\end{array}$ & Sokolow \& Lyon, $1949 .^{2}$ & $\begin{array}{l}\text { Combined } \\
\text { Sokolow\&Lyon } \\
\text { criteria }\end{array}$ \\
\hline RV5/V6, RI/II/III/aVF, RaVL & $\begin{array}{l}\text { Either RV5/V6 }>26 \\
\mathrm{~mm} \text { or any of } \\
\mathrm{RI} / \mathrm{II} / \mathrm{II} / \mathrm{aVF}>20 \\
\mathrm{~mm} \text { or } \mathrm{RaVL}>12 \\
\mathrm{~mm} \\
>93 \mathrm{~mm}(\leq 30\end{array}$ & Blackburn, $1969 .{ }^{15}$ & Minnesota Code \\
\hline Sum of QRS in aVF, V2, V6 & $\begin{array}{l}\text { years }) \\
>59 \mathrm{~mm}(>30 \\
\text { years })\end{array}$ & Manning \& Smiley, $1964 .{ }^{16}$ & \\
\hline $\mathrm{R}$ aVL + S V3 & $\begin{array}{l}>28 \mathrm{~mm} \text { (males) } \\
>20 \mathrm{~mm} \text { (females) }\end{array}$ & Casale et al. $1985 .{ }^{17}$ & Cornell Criteria \\
\hline $\begin{array}{l}\mathrm{R} \text { aVL }+\mathrm{S} V 3 \text {, adj. for } \\
\text { sex/BMI/age }\end{array}$ & $\begin{array}{l}>28 \mathrm{~mm} \text { (males) } \\
>20 \mathrm{~mm} \text { (females) }\end{array}$ & Norman et al. $1993 .^{18}$ & $\begin{array}{l}\text { Framingham } \\
\text { Adjusted Cornel } \\
\text { Criteria }\end{array}$ \\
\hline
\end{tabular}




\begin{tabular}{|c|c|c|c|}
\hline Sum of $[R+Q / S$ wave $)$ in all & $\geq 179 \mathrm{~mm}$ & $\begin{array}{l}\text { Siegel \& Roberts, 1982; Molloy et } \\
\text { (1992 } 19,20\end{array}$ & Sum of 12 leads \\
\hline $\begin{array}{l}\text { Sum of [R or } Q / S \text { wave } \\
\text { (largest) in all } 12 \text { leads] }\end{array}$ & $\geq 179 \mathrm{~mm}$ & $\begin{array}{l}\text { Siegel \& Roberts, } 1982 ; \text { Ha et al. } \\
2018^{20,21}\end{array}$ & $\begin{array}{l}\text { Modified sum of } 12 \\
\text { leads }\end{array}$ \\
\hline $\begin{array}{l}\text { Max S wave in any lead + } \\
\text { SV4 }\end{array}$ & $\begin{array}{l}\geq 28 \mathrm{~mm} \text { (males) } \\
\geq 23 \mathrm{~mm} \text { (females) }\end{array}$ & Peguero et al. $2017 .^{22}$ & Peguero-Lo Presti \\
\hline II. Including QRS-duration & $n=4)$ & & \\
\hline QRS-duration & $\begin{array}{l}>114 \mathrm{~ms} \text { (males) } \\
>97 \mathrm{~ms} \text { (females) }\end{array}$ & Carlsson et al. $2006 .^{23}$ & \\
\hline$(\mathrm{R}$ aVL + S V3) * QRS-dur & $\begin{array}{l}\geq 2436 \mathrm{~mm} / \mathrm{ms} \\
(+8 \mathrm{~mm} \text { for } \\
\text { females) }\end{array}$ & Molloy et al. $1992 .{ }^{19}$ & $\begin{array}{l}\text { Cornell-Voltage- } \\
\text { Product }\end{array}$ \\
\hline $\begin{array}{l}\text { Sum of [R+S wave in all } 12 \\
\text { leads] * }{ }^{*} \text { QRS-dur }\end{array}$ & $\geq 17472 \mathrm{~mm} / \mathrm{ms}$ & Molloy et al. $1992 .{ }^{19}$ & $\begin{array}{l}\text { Sum of } 12 \text { leads- } \\
\text { product }\end{array}$ \\
\hline $\begin{array}{l}\text { Sum of [R or S wave } \\
\text { (largest) in all } 12 \text { leads] * } \\
\text { QRS-dur }\end{array}$ & $\geq 17472 \mathrm{~mm} / \mathrm{ms}$ & $\begin{array}{l}\text { Molloy et al. 1992; Ha et al. } \\
2018 .{ }^{19,21}\end{array}$ & $\begin{array}{l}\text { Modified sum of } 12 \\
\text { leads-product }\end{array}$ \\
\hline III. Point scores (n=2) & & & \\
\hline $\begin{array}{l}\text { Voltage / STT V5-V6 / LAA } \\
\text { P in V1 / axis /QRS-dur }\end{array}$ & Point score $\geq 4$ & Romhilt \& Estes, $1968 .^{24}$ & Romhilt-Estes Score \\
\hline $\begin{array}{l}\text { Voltage-STT V5-V6- } \\
\text { RomhiltEstes }\end{array}$ & $\begin{array}{l}\text { Either of positive = } \\
\text { TRUE }\end{array}$ & Schillaci et al. $1994 .^{25}$ & Perugia Score \\
\hline IV. LV mass equation ( $n=1$ & & & \\
\hline $\begin{array}{l}\text { R V5, S V1, } \max (\text { SIII, QIII), } \\
\text { Tneg(V6), Tpos(aVR), } \\
\text { QRS-dur }\end{array}$ & $\geq 131 \mathrm{~g} / \mathrm{m}^{2}$ (all men) & & \\
\hline $\begin{array}{l}\text { R V5, } \max (S \vee 5, Q \vee 55)) \\
\max (S I, Q I), T p o s(\vee 1) \\
\text { Tneg(aVF), Tpos(V6) }\end{array}$ & $\begin{array}{l}\geq 110 \mathrm{~g} / \mathrm{m}^{2} \\
\text { (white female) }\end{array}$ & Rautaharju et al. $1988 .^{26}$ & $\begin{array}{l}\text { Rautaharju Mass } \\
\text { Equation }\end{array}$ \\
\hline $\begin{array}{l}\mathrm{R} \text { aVL, (R V6, S V2), R V2, } \\
\max (\mathrm{S} V 5, \mathrm{Q} \text { V5), } \\
\text { Tneg(aVL), QRS-dur }\end{array}$ & $\begin{array}{l}\geq 110 \mathrm{~g} / \mathrm{m}^{2} \\
\text { (black female) }\end{array}$ & & \\
\hline
\end{tabular}


Supplemental Table 2. Formulas used for calculations of predictive values, likelihood ratios and post-test probabilities.

Predicitive values

\section{Positive predictive value (PPV)}

Sensitivity $*$ Prevalence

$\overline{(\text { Sensitivity } * \text { Prevalence })+(1-\text { Specificity }) *(1-\text { Prevalence })}$

Positive likelihood ratio (LR+)

$$
\frac{\text { Sensitivity }}{(1-\text { Specificity) }}
$$

Pre-test probability (prevalence)*

$$
\frac{\text { Number with outcome }}{\text { (Total numer of subjects) }}
$$

Post-test odds if positive test

Pre test odds * Positve likelihood ratio

\section{Post-test probability if positive test}

$$
\frac{\text { Post test odds if positive test }}{(1+\text { Post test odds if positive test })}
$$

Negative predictive value (NPV)

$$
\frac{\text { Specificity } *(1-\text { Prevalence })}{(1-\text { Sensitivity })+\text { Specificity } *(1-\text { Prevalence })}
$$

Negative likelihood ratio (LR-)

$$
\frac{(1-\text { Sensitivity })}{\text { Specificity }}
$$

\section{Pre-test odds}

$$
\frac{\text { Prevalence }}{(1-\text { Prevalence })}
$$

Post-test odds if negative test

Pre test odds * Negative likelihood ratio

\section{Post-test probability if negative test}

$$
\frac{\text { Post test odds if negative test }}{(1+\text { Post test odds if negative test })}
$$

*) Outcome in the current study determined by echocardiography as either left ventricular hypertrophy (LVH) or concentric remodelling (mass to volume ratio $\geq 1.05 \mathrm{~g} / \mathrm{mL})$. 


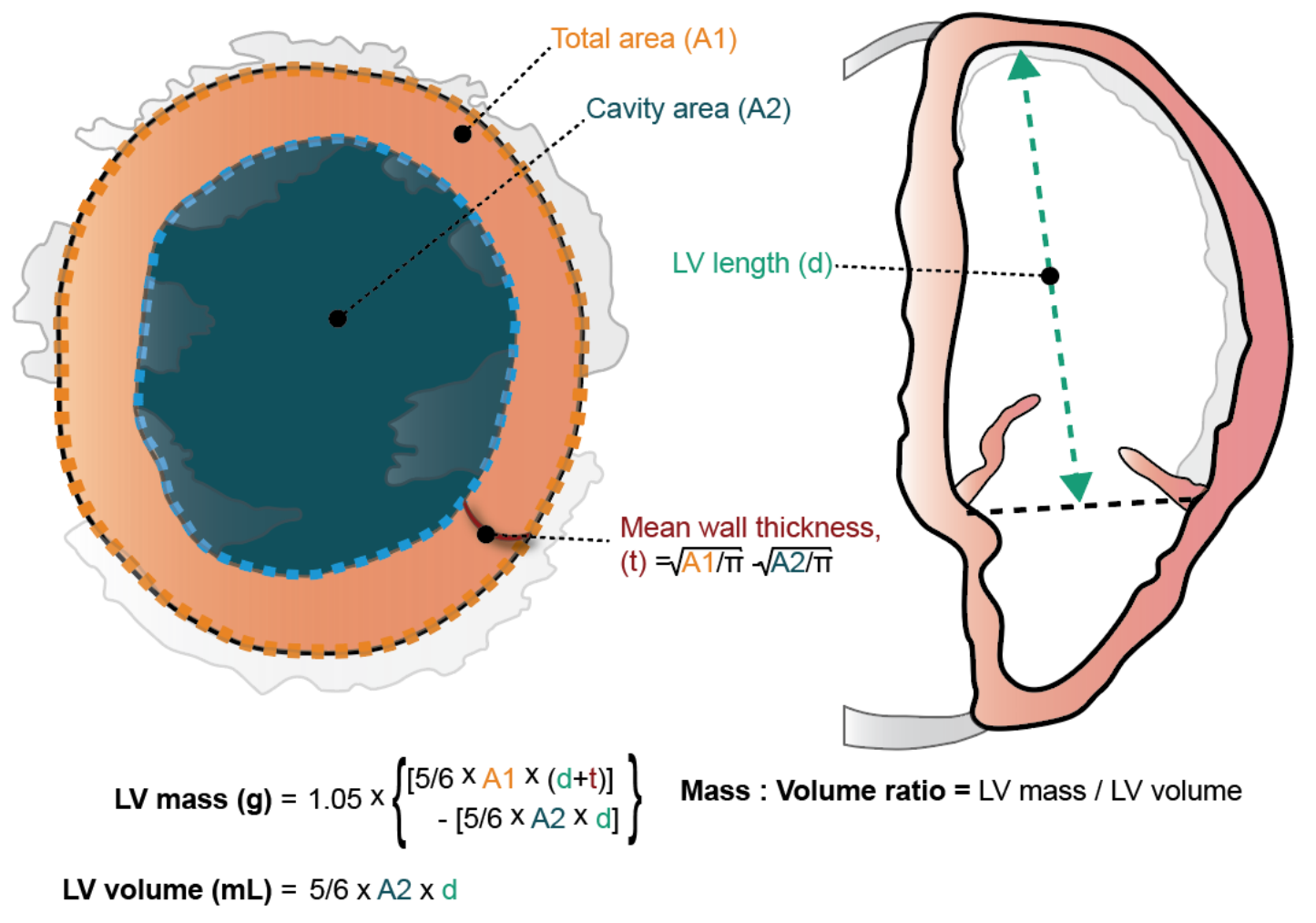

Supplemental Figure 1. Schematic illustration of the measurements and calculations used to determine left ventricular mass (LVM) and mass to volume ratio $(\mathrm{M} / \mathrm{V})$. 
Supplemental Table 3. Logistic regression for categorical variables associated with electrocardiographic left ventricular hypertrophy with international ECG criteria for athletes (in 49 out of 196 athletes).

\begin{tabular}{|c|c|c|c|c|}
\hline & \multicolumn{2}{|c|}{ Univariate } & \multicolumn{2}{|c|}{ Multivariable } \\
\hline & $\beta(95 \% \mathrm{Cl})$ & p & $\beta(95 \% \mathrm{Cl})$ & $\mathbf{p}$ \\
\hline $\mathrm{BMI}>30 \mathrm{~kg} / \mathrm{m}^{2}$ & $0.2(0.1-0.7)$ & 0.007 & $0.3(0.1-1.0)$ & 0.041 \\
\hline Afro-American & $2.5(1.3-4.8)$ & 0.009 & - & - \\
\hline Caucasian & $0.4(0.2-0.8)$ & 0.010 & - & - \\
\hline Football & $0.3(0.1-0.6)$ & $<0.001$ & - & - \\
\hline Basketball & $11.6(3.5-38.0)$ & $<0.001$ & $4.3(1.0-18.3)$ & 0.049 \\
\hline
\end{tabular}


Supplemental Table 4. Bivariate correlations between ECG leads and left ventricular mass indexed by different anthropometric measures and by left-ventricular volume in 196 male athletes.

\section{Limb leads}

$\mathrm{aVL}$

I

aVR

II

aVF

III
LVM[BSA]

$.20^{\dagger}(\mathrm{R})$

$.26^{\dagger^{*}}(\mathrm{R})$

$.16^{*}(R)$

$-$

LVM[BSA]

$.19^{\dagger}(\mathrm{S})$

$.19^{\dagger}(\mathrm{S})$

V2

V3

$\sqrt{ } 4$

V5

V6

$30^{\dagger^{*}}(\mathrm{R})$
LVM[BSA ${ }^{1.5}$ ]

$.15^{*}(\mathrm{R})$

$.21^{\dagger}(\mathrm{R})$

$.22^{\dagger}(\mathrm{R})$

$.17^{*}(\mathrm{R})$

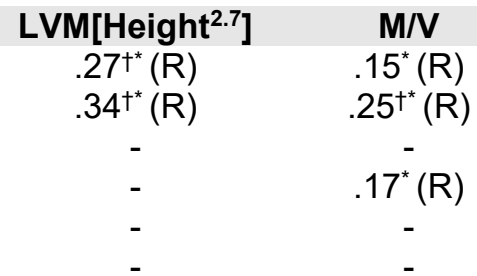

LVM[Height $\left.{ }^{2.7}\right] \quad M / V$

$.16^{\star}(\mathrm{S})$

$.16^{*}(\mathrm{R})$

$33^{t^{*}}(\mathrm{R})$

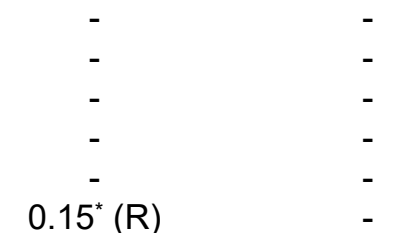

$.27^{\dagger^{*}}(\mathrm{R}) \quad .30^{\dagger^{*}}(\mathrm{R}) \quad .27^{\dagger^{*}}(\mathrm{R})$

$0.15^{*}(\mathrm{R})$

absolute, positive value of either of $S$ - or $R$ wave is presented as noted in parenthesis and corresponds to its physiological association with LV depolarization. 

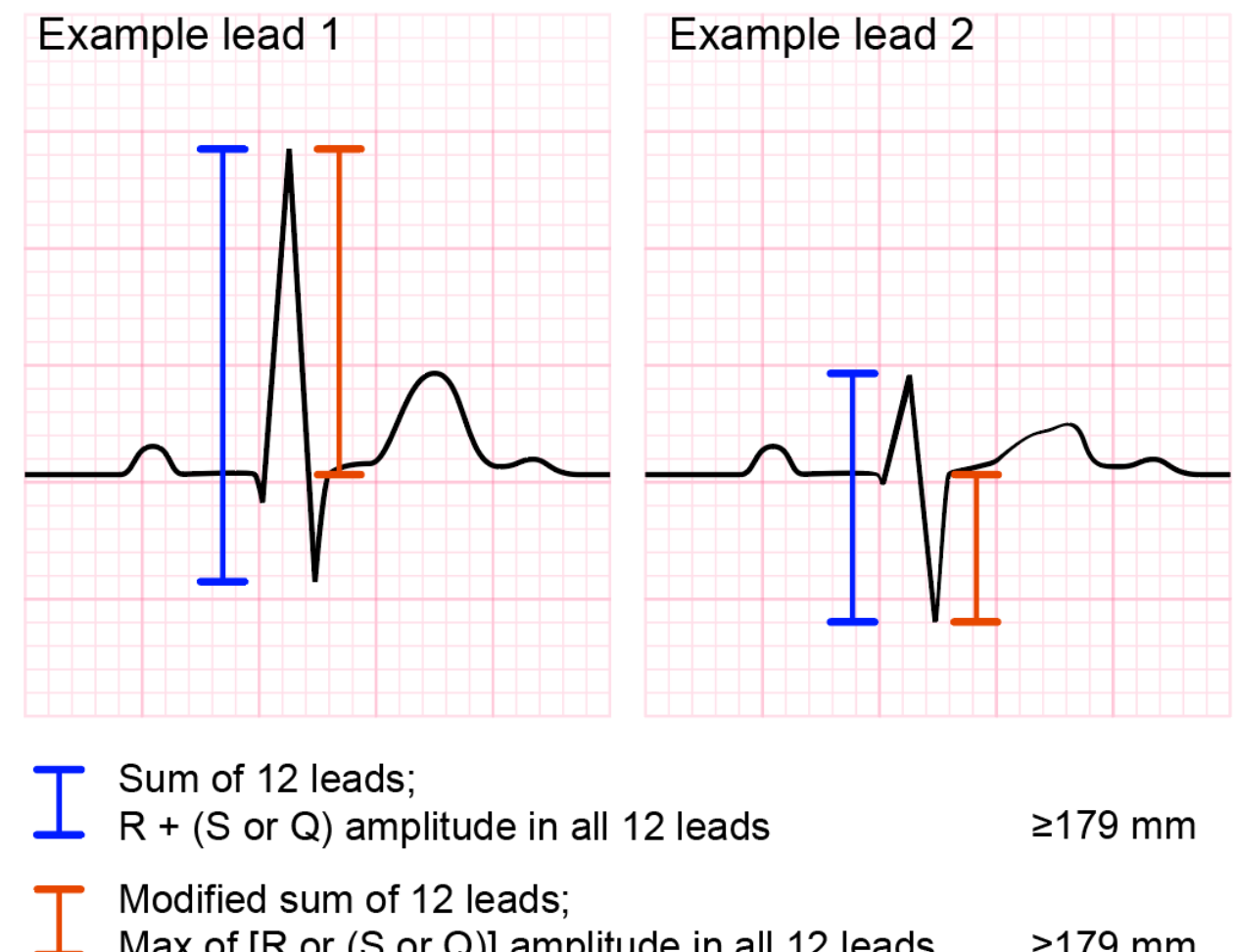

Sum of 12 leads;

$\mathrm{R}+(\mathrm{S}$ or $\mathrm{Q})$ amplitude in all 12 leads

$\geq 179 \mathrm{~mm}$

T Modified sum of 12 leads;

Supplemental Figure 2. Different definitions of the Sum of 12 leads criterion used in this manuscript.

Blue color reflects the originally described method for summarizing the voltage in the 12 leads,(29) where the absolute values of the peak negative and positive deflections are first summarized in each lead. In the modified version,(31) the maximal absolute deflection in each lead are summarized from all 12 leads. Note that the threshold for left ventricular hypertrophy $(\geq 179 \mathrm{~mm})$ is identical with each of the two criteria. 
Supplemental Table 5. Diagnostic precision of different ECG criteria for detecting the 11 out of 196 male athletes with left ventricular hypertrophy as defined per current echocardiography guidelines.

\begin{tabular}{|c|c|c|c|c|c|c|c|c|c|}
\hline & Lead(s) & $\begin{array}{c}\text { N } \\
\text { pos. } \\
(\%)\end{array}$ & $\begin{array}{c}\text { AUC } \\
(95 \% \mathrm{Cl})\end{array}$ & $\begin{array}{c}\text { Sens } \\
.\end{array}$ & Spec. & PPV & NPV & LR+ & LR- \\
\hline \multicolumn{10}{|c|}{ Limb lead voltage (7) } \\
\hline \multicolumn{10}{|c|}{ One lead (5) } \\
\hline Gubner 1943 & $\mathrm{R} \mathrm{I}>15 \mathrm{~mm}$ & 0 & $\begin{array}{c}0.50 \\
(0.32-.68)\end{array}$ & - & - & - & - & - & - \\
\hline Sokolov 1949 & $\mathrm{R}$ aVL >11 mm & $\begin{array}{c}1 \\
(0.5 \%)\end{array}$ & $\begin{array}{c}0.50 \\
(0.32-0.67)\end{array}$ & $0 \%$ & $99.5 \%$ & $0 \%$ & $94 \%$ & .0 & 1.0 \\
\hline $\begin{array}{l}\text { Goldberger } \\
1949\end{array}$ & $\mathrm{R}$ aVF $>20 \mathrm{~mm}$ & $\begin{array}{c}18 \\
(9 \%)\end{array}$ & $\begin{array}{c}0.55 \\
(0.36-0.73)\end{array}$ & $18 \%$ & $91 \%$ & $11 \%$ & $95 \%$ & 2.1 & 0.9 \\
\hline Schack 1950 & $\mathrm{Q}$ or $\mathrm{S}$ aVR $>19 \mathrm{~mm}$ & 0 & $\begin{array}{c}0.50 \\
(0.32-0.68)\end{array}$ & - & - & - & - & - & - \\
\hline Romhilt 1968 & $\mathrm{R}$ or $\mathrm{S}$ in any limb lead $>19 \mathrm{~mm}$ & $\begin{array}{c}38 \\
(19 \%)\end{array}$ & $\begin{array}{c}0.54 \\
(0.36-0.72)\end{array}$ & $27 \%$ & $81 \%$ & $8 \%$ & $95 \%$ & 1.4 & 0.9 \\
\hline \multicolumn{10}{|l|}{$>1$ lead (2) } \\
\hline Lewis 1914 & $(\mathrm{R} I-S \mathrm{I})+(\mathrm{S} I I I-R \mathrm{III})>16 \mathrm{~mm}$ & $\begin{array}{c}56 \\
(29 \%)\end{array}$ & $\begin{array}{c}0.54 \\
(0.36-0.72)\end{array}$ & $36 \%$ & $72 \%$ & $7 \%$ & $95 \%$ & 1.3 & 0.9 \\
\hline Gubner 1943 & $\mathrm{R}$ I + S III >25 mm & $\begin{array}{c}1 \\
(0.5 \%)\end{array}$ & $\begin{array}{c}0.50 \\
(0.32-0.67)\end{array}$ & $0 \%$ & $99.5 \%$ & $0 \%$ & $94 \%$ & .0 & 1.0 \\
\hline \multicolumn{10}{|c|}{ Precordial lead voltage (14) } \\
\hline \multicolumn{10}{|l|}{ One lead (6) } \\
\hline Wilson 1944 & $\mathrm{~S} \vee 1>23 \mathrm{~mm}$ & $\begin{array}{c}3 \\
(2 \%)\end{array}$ & $\begin{array}{c}0.54 \\
(0.35-0.73)\end{array}$ & $9 \%$ & $99 \%$ & $33 \%$ & $95 \%$ & 8.4 & 0.9 \\
\hline Mazzoleni 1964 & $\mathrm{~S} V 2>25 \mathrm{~mm}$ & $\begin{array}{c}29 \\
(15 \%)\end{array}$ & $\begin{array}{c}0.57 \\
(0.38-.75)\end{array}$ & $27 \%$ & $86 \%$ & $10 \%$ & $95 \%$ & 1.9 & 0.9 \\
\hline Wilson 1944 & $\mathrm{R} V 5>33 \mathrm{~mm}$ & $\begin{array}{c}4 \\
(2 \%)\end{array}$ & $\begin{array}{c}0.49 \\
(0.32-0.66)\end{array}$ & $0 \%$ & $98 \%$ & $0 \%$ & $94 \%$ & .0 & 1.0 \\
\hline Wilson 1944 & $\mathrm{R} V 6>25 \mathrm{~mm}$ & $\begin{array}{c}7 \\
(4 \%)\end{array}$ & $\begin{array}{c}0.53 \\
(0.35-0.71)\end{array}$ & $9 \%$ & $97 \%$ & $14 \%$ & $95 \%$ & 2.8 & 0.9 \\
\hline Grant 1957 & $\mathrm{R}+\mathrm{S}$ any precordial lead $>35 \mathrm{~mm}$ & $\begin{array}{c}55 \\
(28 \%)\end{array}$ & $\begin{array}{c}0.64 \\
(0.46-0.82)\end{array}$ & $55 \%$ & $74 \%$ & $11 \%$ & $96 \%$ & 2.1 & 0.6 \\
\hline McPhie 1958 & $\mathrm{R}$ any precordial lead >26 mm & $\begin{array}{c}53 \\
(27 \%)\end{array}$ & $\begin{array}{c}0.65 \\
(0.47-0.82)\end{array}$ & $55 \%$ & $75 \%$ & $11 \%$ & $97 \%$ & 2.2 & 0.6 \\
\hline \multicolumn{10}{|l|}{$>1$ lead (8) } \\
\hline Sokolov 1949 & $\mathrm{~S} V 1+\mathrm{R} V 5>35 \mathrm{~mm}$ & $\begin{array}{c}48 \\
(24 \%)\end{array}$ & $\begin{array}{c}0.61 \\
(0.43-0.79)\end{array}$ & $46 \%$ & $77 \%$ & $10 \%$ & $96 \%$ & 2.0 & 0.7 \\
\hline
\end{tabular}




\begin{tabular}{|c|c|c|c|c|c|c|c|c|c|}
\hline Sharma 2018 & $\mathrm{~S} V 1+\mathrm{R} V 5 / \mathrm{V} 6>35 \mathrm{~mm}$ & $\begin{array}{c}49 \\
(25 \%)\end{array}$ & $\begin{array}{c}0.61 \\
(0.43-0.79)\end{array}$ & $46 \%$ & $76 \%$ & $10 \%$ & $96 \%$ & 1.9 & 0.7 \\
\hline Wolff 1956 & $\mathrm{~S} \mathrm{~V} 2+\mathrm{R} V 4 / \mathrm{V} 5>45 \mathrm{~mm}$ & $\begin{array}{c}52 \\
(27 \%)\end{array}$ & $\begin{array}{c}0.55 \\
(0.37-0.73)\end{array}$ & $36 \%$ & $74 \%$ & $8 \%$ & $95 \%$ & 1.4 & 0.9 \\
\hline Romhilt 1969 & $\mathrm{~S} V 2+\mathrm{R} V 5 / \mathrm{V} 6>45 \mathrm{~mm}$ & $\begin{array}{c}41 \\
(21 \%)\end{array}$ & $\begin{array}{c}0.58 \\
(0.40-0.77)\end{array}$ & $36 \%$ & $80 \%$ & $10 \%$ & $95 \%$ & 1.8 & 0.8 \\
\hline Murphy 1984 & $\mathrm{~S} V 1 / \mathrm{V} 2+\mathrm{R} V 5 / \mathrm{V} 6>40 \mathrm{~mm}$ & $\begin{array}{c}68 \\
(35 \%)\end{array}$ & $\begin{array}{c}0.65 \\
(0.48-0.82)\end{array}$ & $64 \%$ & $67 \%$ & $10 \%$ & $97 \%$ & 1.9 & 0.5 \\
\hline Grant 1957 & $\mathrm{~S} V 1 / \mathrm{V} 2+\mathrm{R} V 6>40 \mathrm{~mm}$ & $\begin{array}{c}35 \\
(18 \%)\end{array}$ & $\begin{array}{c}0.60 \\
(0.41-0.78)\end{array}$ & $36 \%$ & $83 \%$ & $11 \%$ & $96 \%$ & 2.2 & 0.8 \\
\hline Sokolov 1949 & $\mathrm{R}$ V5/V6 >26 mm & $\begin{array}{c}28 \\
(14 \%)\end{array}$ & $\begin{array}{c}0.67 \\
(0.48-0.85)\end{array}$ & $46 \%$ & $88 \%$ & $18 \%$ & $96 \%$ & 3.7 & 0.6 \\
\hline Wilson 1944 & $\begin{array}{l}\text { Either of: S V1 >23 mm, RV5 >33 mm, R } \\
\text { V6 }>25 \mathrm{~mm}\end{array}$ & $\begin{array}{c}12 \\
(6 \%)\end{array}$ & $\begin{array}{c}0.56 \\
(0.37-0.75)\end{array}$ & $18 \%$ & $95 \%$ & $17 \%$ & $95 \%$ & 3.4 & 0.9 \\
\hline Holt 1962 & R V6:R V5 (ratio) >1.0 & $\begin{array}{c}7 \\
(4 \%)\end{array}$ & $\begin{array}{c}0.53 \\
(0.35-0.71)\end{array}$ & $9 \%$ & $97 \%$ & $14 \%$ & $95 \%$ & 2.8 & 0.9 \\
\hline \multicolumn{10}{|c|}{ Limb and precordial leads (8) } \\
\hline Sokolov 1949 & $\begin{array}{l}\text { Either of: SV1+RV5 >35 mm, RV5/V6 } \\
>26 \mathrm{~mm}, \mathrm{RaVL}>11 \mathrm{~mm}\end{array}$ & $\begin{array}{c}53 \\
(27 \%)\end{array}$ & $\begin{array}{c}0.69 \\
(0.52-0.86)\end{array}$ & $64 \%$ & $75 \%$ & $13 \%$ & $97 \%$ & 2.6 & 0.5 \\
\hline Blackburn 1969 & $\begin{array}{l}\mathrm{RV} 5 / \mathrm{V} 6>26 \mathrm{~mm}, \mathrm{RI} / \mathrm{II} / \mathrm{Il} / \mathrm{aVF}>20 \mathrm{~mm}, \\
\mathrm{RaVL}>12 \mathrm{~mm}\end{array}$ & $\begin{array}{c}50 \\
(25 \%)\end{array}$ & $\begin{array}{c}0.61 \\
(0.42-0.79)\end{array}$ & $46 \%$ & $76 \%$ & $10 \%$ & $96 \%$ & 1.9 & 0.7 \\
\hline Manning 1964 & $\begin{array}{l}\text { Sum of } Q R S \text { in aVF, V2, V6 >93 mm } \\
(\leq 30 \text { years), } \\
>59 \mathrm{~mm}(>30 \text { years })\end{array}$ & $\begin{array}{c}1 \\
(0.5 \%)\end{array}$ & $\begin{array}{c}0.50 \\
(0.32-0.67)\end{array}$ & $0 \%$ & $99.5 \%$ & $0 \%$ & $94 \%$ & .0 & 1.0 \\
\hline Casale 1985 & $\begin{array}{l}\mathrm{R} \text { aVL }+\mathrm{S} V 3>28 \mathrm{~mm} \text { (males) } \\
>20 \mathrm{~mm} \text { (females) }\end{array}$ & $\begin{array}{c}6 \\
(3 \%)\end{array}$ & $\begin{array}{c}0.53 \\
(0.35-0.72)\end{array}$ & $9 \%$ & $97 \%$ & $17 \%$ & $95 \%$ & 3.4 & 0.9 \\
\hline Norman 1993 & $\begin{array}{l}\mathrm{R} \text { aVL }+\mathrm{S} \vee 3, \text { adj. for BMl/age }>28 \mathrm{~mm} \\
\text { (males), }>20 \mathrm{~mm} \text { (females) }\end{array}$ & $\begin{array}{c}18 \\
(9 \%)\end{array}$ & $\begin{array}{c}0.55 \\
(0.36-0.73)\end{array}$ & $18 \%$ & $91 \%$ & $11 \%$ & $95 \%$ & 2.1 & 0.9 \\
\hline $\begin{array}{l}\text { Siegel 1982, } \\
\text { Malloy } 1992\end{array}$ & $\begin{array}{l}\text { Sum of }(R+S \text { or } Q) \text { in all } 12 \text { leads } \geq 179 \\
\mathrm{~mm}\end{array}$ & $\begin{array}{c}134 \\
(68 \%)\end{array}$ & $\begin{array}{c}0.62 \\
(0.47-0.77)\end{array}$ & $91 \%$ & $33 \%$ & $7 \%$ & $98 \%$ & 1.4 & 0.3 \\
\hline $\begin{array}{l}\text { Siegel 1982, } \\
\text { Ha } 2017\end{array}$ & $\begin{array}{l}\text { Sum of (max of } Q, R \text { or } S \text { ) in all } 12 \text { leads } \\
\geq 179 \mathrm{~mm}\end{array}$ & $\begin{array}{c}57 \\
(29 \%)\end{array}$ & $\begin{array}{c}0.64 \\
(0.46-0.81)\end{array}$ & $55 \%$ & $72 \%$ & $11 \%$ & $96 \%$ & 2.0 & 0.6 \\
\hline Peguero 2017 & $\begin{array}{l}\text { Max } S \text { any lead }+S \vee 4, \geq 28 \mathrm{~mm} \text { (males), } \\
\geq 23 \mathrm{~mm} \text { (females) }\end{array}$ & $\begin{array}{c}69 \\
(35 \%)\end{array}$ & $\begin{array}{c}0.65 \\
(0.48-0.82)\end{array}$ & $64 \%$ & $67 \%$ & $10 \%$ & $97 \%$ & 1.9 & 0.6 \\
\hline \multicolumn{10}{|l|}{ Non-voltage (1) } \\
\hline Carlsson 2006 & $\begin{array}{l}\text { QRS-duration, >114 ms (males), >97 ms } \\
\text { (females) }\end{array}$ & $\begin{array}{c}20 \\
(10 \%)\end{array}$ & $\begin{array}{c}0.49 \\
(0.32-0.67)\end{array}$ & $9 \%$ & $90 \%$ & $5 \%$ & $94 \%$ & 0.9 & 1.0 \\
\hline \multicolumn{10}{|c|}{ 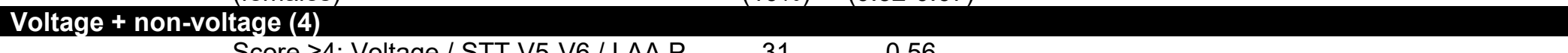 } \\
\hline Romhilt 1968 & $\begin{array}{l}\text { Score } \geq 4 \text { : Voltage / STT V5-V6 / LAA P } \\
\text { in V1 / axis /QRS-dur }\end{array}$ & $\begin{array}{c}31 \\
(16 \%)\end{array}$ & $\begin{array}{c}0.56 \\
(0.38-0.75)\end{array}$ & $27 \%$ & $85 \%$ & $10 \%$ & $95 \%$ & 1.8 & 0.9 \\
\hline
\end{tabular}


Schillaci 1994

Molloy 1962

Okin 1995

Molloy 1962

Molloy 1962

\section{Ha 2017 \\ Mass equation/prediction (1)}

Rautaharju 1988

$\geq 131 \mathrm{~g} / \mathrm{m}^{2}$ (men), $\geq 110 \mathrm{~g} / \mathrm{m}^{2}$ (female)

1988 R V5, S V1, $\max (S I I I$, QIII), Tneg(V6)

Tpos(aVR), QRS-dur

Romhiltestes $\geq 4$ oltage-STT V5-V6

Estes $\geq 4$

+ S V3) * QRS-dur, $\geq 2436$

12 leads * QRS-dur, $\geq 17472$

$\mathrm{mm} / \mathrm{ms}$

Sum of 12 leads (Vic) * QRS-dur,

(18\%)

$32^{\mathrm{a}} \quad 0.60$

$(18 \%) \quad(0.41-0.79)$

$12 \%$

2.2

a) Rautaharju score not calculated for 15 athletes of other than Caucasian or Afro-American ethnicity. Current echocardiographic guidelines (Lang et al. 2015) define LVH in males as a LVM[BSA] $>102 \mathrm{~g} / \mathrm{m}^{2}$. AUC, area under the curve; Sens/Spec, sensitivity/specificity; PPV/NPV, positive and negative predictive value; LR+/LR-, positive and negative likelihood ratio. Red colour indicates $95 \% \mathrm{Cl}$ not overlapping 0.50 . 
(A) Post-test probability of left ventricular hypertrophy (LVM[BSA] $>102 \mathrm{~g} / \mathrm{m}^{2}$ ) based on positive or negative ECG for LVH

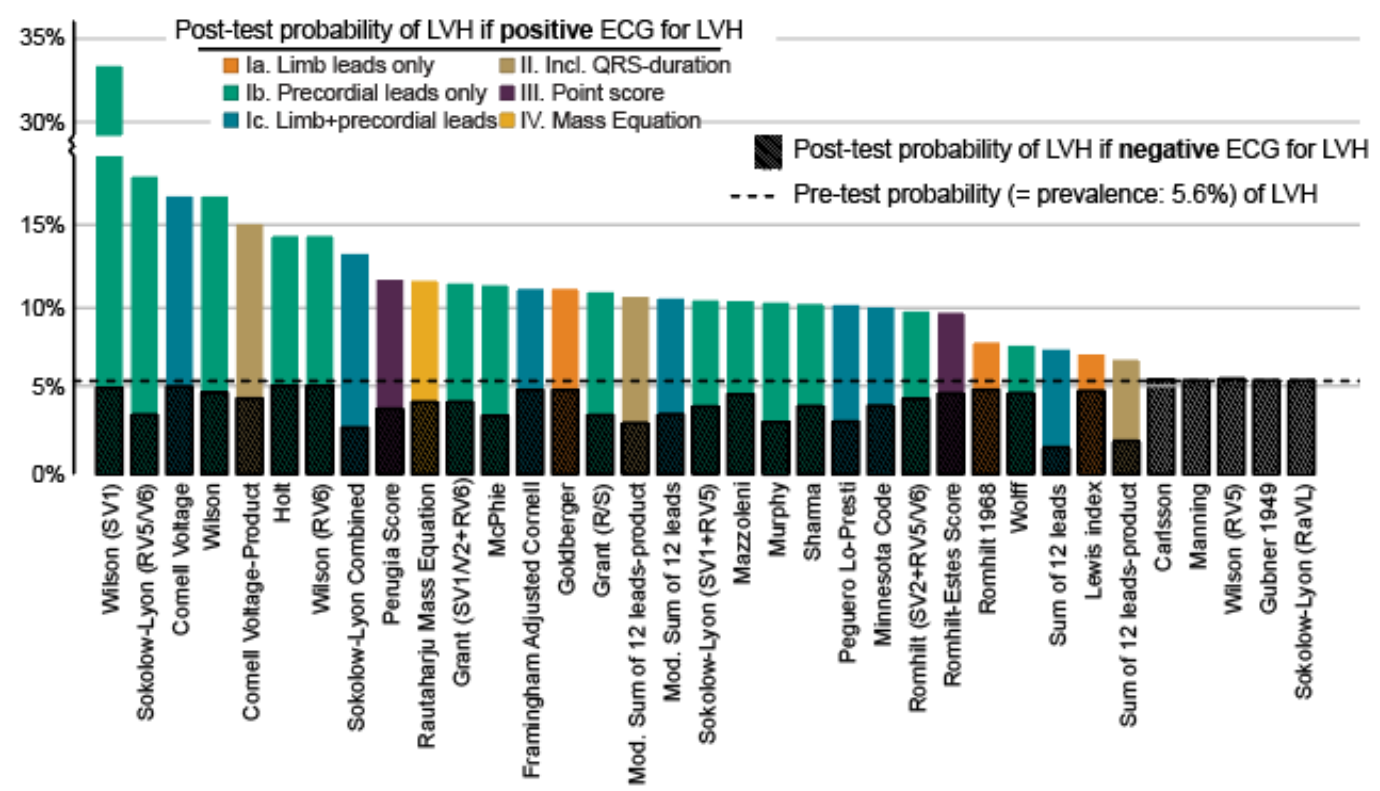

(B) Post-test probability of a concentric phenotype ( $M / \mathrm{V} \geq 1.05 \mathrm{~g} / \mathrm{mL})$ based on positive or negative ECG for LVH

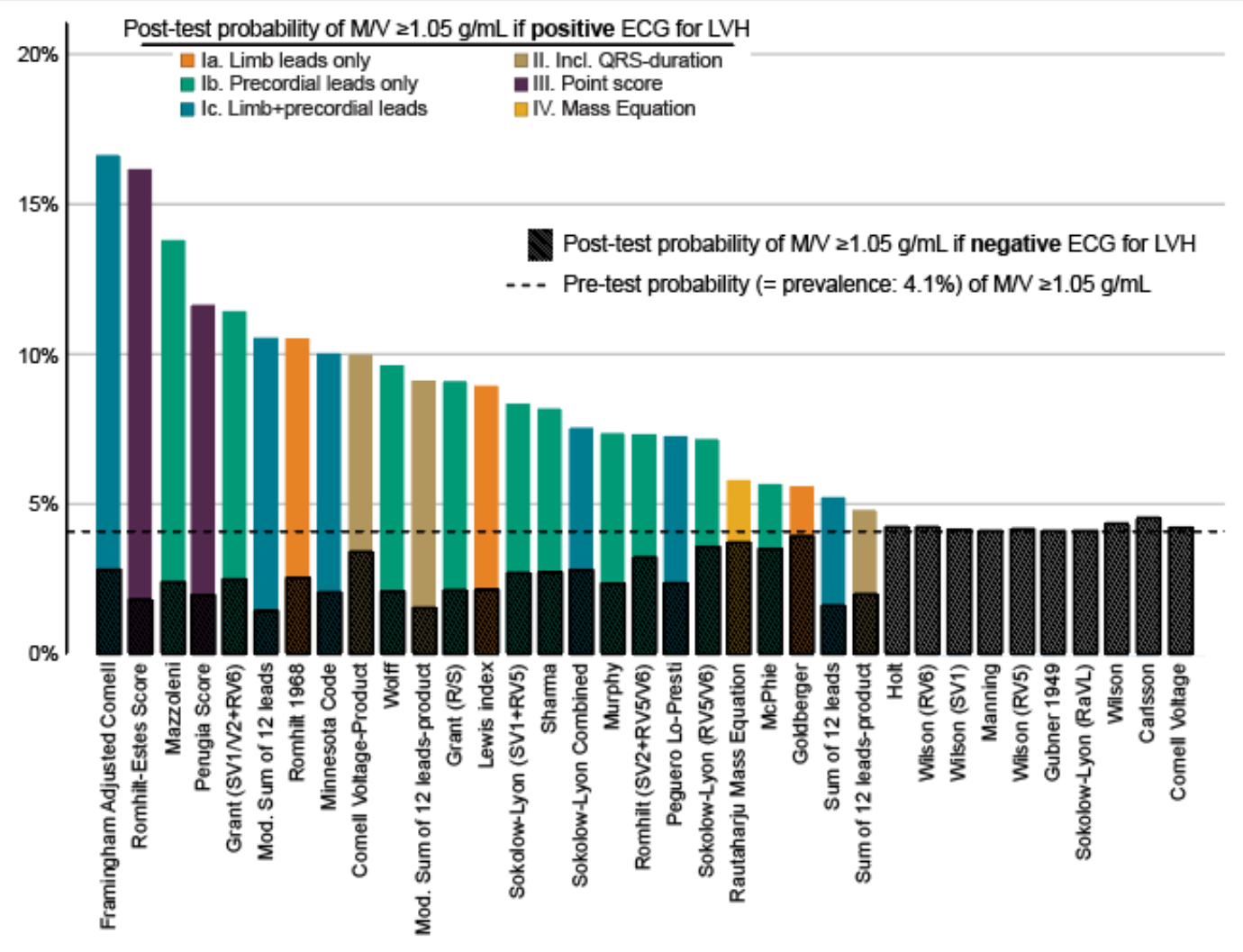

Supplemental Figure 3. Post-test probability of left ventricular hypertrophy ( $L V H$, panel A) and a concentric phenotype (M/V $\geq 1.05 \mathrm{~g} / \mathrm{mL}$, panel B) based on a positive or negative ECG based on ECG criterion's ECG-LVH threshold.

Note that for a few criteria, a positive test decreased the probability of LVH or high $\mathrm{M} / \mathrm{V}$. The pre-test probability of disease was set to the prevalence of LVH (5.6\%) and high M/V (4.1\%) and is represented by the horizontal, dashed line. 
Supplemental Table 6. Diagnostic precision of different ECG criteria for detecting the 8 out of 196 male athletes with a mass to volume ratio in the upper $95^{\text {th }}$ percentile.

\begin{tabular}{|c|c|c|c|c|c|c|c|c|c|}
\hline - : & Lead(s) & $\begin{array}{l}\mathrm{N}(\%) \\
\text { pos. }\end{array}$ & AUC & Sens & Spec & PPV & NPV & LR+ & LR- \\
\hline \multirow{2}{*}{\multicolumn{10}{|c|}{$\begin{array}{l}\text { Limb lead voltage (7) } \\
\text { One lead (5) }\end{array}$}} \\
\hline & & & & & & & & & \\
\hline Gubner 1943 & $\mathrm{R} \mathrm{I}>15 \mathrm{~mm}$ & 0 & $\begin{array}{c}0.50 \\
(0.30-0.71)\end{array}$ & - & - & - & - & - & - \\
\hline Sokolov 1949 & $\mathrm{R}$ aVL $>11 \mathrm{~mm}$ & $\begin{array}{c}1 \\
(0.5 \%)\end{array}$ & $\begin{array}{c}0.50 \\
(0.29-0.71)\end{array}$ & $0 \%$ & $\begin{array}{c}100 \\
\%\end{array}$ & $0 \%$ & $96 \%$ & .0 & 1.0 \\
\hline $\begin{array}{l}\text { Goldberger } \\
1949\end{array}$ & $\mathrm{R}$ aVF $>20 \mathrm{~mm}$ & $\begin{array}{c}18 \\
(9 \%)\end{array}$ & $\begin{array}{c}0.52 \\
(0.31-0.73)\end{array}$ & $13 \%$ & $91 \%$ & $6 \%$ & $96 \%$ & 1.4 & 1.0 \\
\hline Schack 1950 & $\mathrm{Q}$ or $\mathrm{S}$ aVR $>19 \mathrm{~mm}$ & 0 & $\begin{array}{c}0.50 \\
(0.31-0.71)\end{array}$ & - & - & - & - & - & - \\
\hline Romhilt 1968 & $\mathrm{R}$ or $\mathrm{S}$ in any limb lead $>19 \mathrm{~mm}$ & $\begin{array}{c}38 \\
(19 \%)\end{array}$ & $\begin{array}{c}0.66 \\
(0.45-0.87)\end{array}$ & $50 \%$ & $82 \%$ & $11 \%$ & $97 \%$ & 2.8 & 0.6 \\
\hline \multicolumn{10}{|l|}{$>1$ lead $(2)$} \\
\hline Lewis 1914 & $(R I-S I)+(S I I I-R ~ I I I)>16 \mathrm{~mm}$ & $\begin{array}{c}56 \\
(29 \%)\end{array}$ & $\begin{array}{c}0.68 \\
(0.48-0.88)\end{array}$ & $63 \%$ & $73 \%$ & $9 \%$ & $98 \%$ & 2.3 & 0.5 \\
\hline Gubner 1949 & $\mathrm{R}$ I + S III >25 mm & $\begin{array}{c}1 \\
(0.5 \%)\end{array}$ & $\begin{array}{c}0.50 \\
(0.29-0.69)\end{array}$ & $0 \%$ & $\begin{array}{c}100 \\
\%\end{array}$ & $0 \%$ & $96 \%$ & .0 & 1.0 \\
\hline \multicolumn{10}{|c|}{ Precordial lead voltage (14) } \\
\hline Wilson 1944 & $\mathrm{~S} \vee 1>23 \mathrm{~mm}$ & $\begin{array}{c}3 \\
(2 \%)\end{array}$ & $\begin{array}{c}0.49 \\
(0.29-0.69)\end{array}$ & $0 \%$ & $98 \%$ & $0 \%$ & $96 \%$ & .0 & 1.0 \\
\hline Mazzoleni 1964 & $\mathrm{~S} \mathrm{~V} 2>25 \mathrm{~mm}$ & $\begin{array}{c}29 \\
(15 \%)\end{array}$ & $\begin{array}{c}0.68 \\
(0.47-0.90)\end{array}$ & $50 \%$ & $87 \%$ & $14 \%$ & $98 \%$ & 3.8 & 0.6 \\
\hline Wilson 1944 & R V5 >33 mm & $\begin{array}{c}4 \\
(2 \%)\end{array}$ & $\begin{array}{c}0.49 \\
(0.29-0.69)\end{array}$ & $0 \%$ & $98 \%$ & $0 \%$ & $96 \%$ & .0 & 1.0 \\
\hline Wilson 1944 & $\mathrm{R} \vee 6>25 \mathrm{~mm}$ & $\begin{array}{c}7 \\
(4 \%)\end{array}$ & $\begin{array}{c}0.48 \\
(0.28-0.68)\end{array}$ & $0 \%$ & $96 \%$ & $0 \%$ & $96 \%$ & .0 & 1.0 \\
\hline Grant 1957 & $\mathrm{R}+\mathrm{S}$ any precordial lead $>35 \mathrm{~mm}$ & $\begin{array}{c}55 \\
(28 \%)\end{array}$ & $\begin{array}{c}0.68 \\
(0.48-0.88)\end{array}$ & $63 \%$ & $73 \%$ & $9 \%$ & $98 \%$ & 2.4 & 0.5 \\
\hline McPhie 1958 & $\mathrm{R}$ any precordial lead $>26 \mathrm{~mm}$ & $\begin{array}{c}53 \\
(27 \%)\end{array}$ & $\begin{array}{c}0.56 \\
(0.34-0.77)\end{array}$ & $38 \%$ & $73 \%$ & $6 \%$ & $97 \%$ & 1.4 & 0.9 \\
\hline \multicolumn{10}{|l|}{$>1$ lead (9) } \\
\hline Sokolov 1949 & $\mathrm{~S} \vee 1+\mathrm{R} V 5>35 \mathrm{~mm}$ & $\begin{array}{c}48 \\
(24 \%)\end{array}$ & $\begin{array}{c}0.63 \\
(0.42-0.84)\end{array}$ & $50 \%$ & $77 \%$ & $8 \%$ & $97 \%$ & 2.1 & 0.7 \\
\hline Sharma 2018 & $\mathrm{~S} V 1+\mathrm{R}$ V5/V6 >35 mm & $\begin{array}{c}49 \\
(25 \%)\end{array}$ & $\begin{array}{c}0.63 \\
(0.42-0.84)\end{array}$ & $50 \%$ & $76 \%$ & $8 \%$ & $97 \%$ & 2.1 & 0.7 \\
\hline
\end{tabular}




\begin{tabular}{|c|c|c|c|c|c|c|c|c|c|}
\hline Wolff 1956 & $\mathrm{~S} V 2+\mathrm{R} V 4 / \mathrm{V} 5>45 \mathrm{~mm}$ & $\begin{array}{c}52 \\
(27 \%)\end{array}$ & $\begin{array}{c}0.69 \\
(0.49-0.88)\end{array}$ & $63 \%$ & $75 \%$ & $10 \%$ & $98 \%$ & 2.5 & 0.5 \\
\hline Romhilt 1969 & $\mathrm{~S} V 2+\mathrm{R} V 5 / \mathrm{V} 6>45 \mathrm{~mm}$ & $\begin{array}{c}41 \\
(21 \%)\end{array}$ & $\begin{array}{c}0.59 \\
(0.37-0.80)\end{array}$ & $38 \%$ & $80 \%$ & $7 \%$ & $97 \%$ & 1.9 & 0.8 \\
\hline Murphy 1984 & $\mathrm{~S} V 1 / \mathrm{V} 2+\mathrm{R} V 5 / \mathrm{V} 6>35 \mathrm{~mm}$ & $\begin{array}{c}68 \\
(35 \%)\end{array}$ & $\begin{array}{c}0.65 \\
(0.45-0.84)\end{array}$ & $63 \%$ & $44 \%$ & $7 \%$ & $98 \%$ & 1.9 & 0.6 \\
\hline Grant 1957 & $\mathrm{~S} V 1 / \mathrm{V} 2+\mathrm{R} V 6>40 \mathrm{~mm}$ & $\begin{array}{c}35 \\
(18 \%)\end{array}$ & $\begin{array}{c}0.67 \\
(0.45-0.88)\end{array}$ & $50 \%$ & $84 \%$ & $11 \%$ & $98 \%$ & 3.0 & 0.6 \\
\hline Sokolov 1949 & $\mathrm{R}$ V5/V6 >26 mm & $\begin{array}{c}28 \\
(14 \%)\end{array}$ & $\begin{array}{c}0.56 \\
(0.41-0.83)\end{array}$ & $25 \%$ & $86 \%$ & $7 \%$ & $96 \%$ & 1.8 & 0.9 \\
\hline Wilson 1944 & $\begin{array}{l}\text { Either of: S V1 }>23 \mathrm{~mm}, \mathrm{RV} 5>33 \\
\mathrm{~mm}, \mathrm{R} \text { V } 6>25 \mathrm{~mm}\end{array}$ & $\begin{array}{c}12 \\
(6 \%)\end{array}$ & $\begin{array}{c}0.47 \\
(0.28-0.66)\end{array}$ & $0 \%$ & $94 \%$ & $0 \%$ & $96 \%$ & .0 & 1.1 \\
\hline Holt 1962 & R V6:R V5 (ratio) >1.0 & $\begin{array}{c}7 \\
(4 \%)\end{array}$ & $\begin{array}{c}0.48 \\
(0.28-0.68)\end{array}$ & $0 \%$ & $96 \%$ & $0 \%$ & $96 \%$ & .0 & 1.0 \\
\hline \multicolumn{10}{|c|}{ Limb and precordial leads (8) } \\
\hline Sokolov 1949 & $\begin{array}{l}\text { Either of: SV1+RV5 >35 mm, } \\
\text { RV5/V6 > } 26 \mathrm{~mm}, \mathrm{RaVL}>11 \mathrm{~mm}\end{array}$ & $\begin{array}{c}53 \\
(27 \%)\end{array}$ & $\begin{array}{c}0.62 \\
(0.41-0.83)\end{array}$ & $50 \%$ & $74 \%$ & $8 \%$ & $97 \%$ & 1.9 & 0.7 \\
\hline Blackburn 1969 & $\begin{array}{l}\mathrm{RV} 5 / \mathrm{V} 6>26 \mathrm{~mm}, \mathrm{RI} / \mathrm{II} / \mathrm{II} / \mathrm{aVF}>20 \\
\mathrm{~mm}, \mathrm{RaVL}>12 \mathrm{~mm}\end{array}$ & $\begin{array}{c}50 \\
(25 \%)\end{array}$ & $\begin{array}{c}0.69 \\
(0.49-0.89)\end{array}$ & $63 \%$ & $76 \%$ & $10 \%$ & $98 \%$ & 2.6 & 0.5 \\
\hline Manning 1964 & $\begin{array}{l}\text { Sum of QRS in aVF, V2, V6 }>93 \\
\mathrm{~mm}(\leq 30 \text { years), }>59 \mathrm{~mm}(>30 \\
\text { years) }\end{array}$ & $\begin{array}{c}1 \\
(0.5 \%)\end{array}$ & $\begin{array}{c}0.50 \\
(0.29-0.70)\end{array}$ & $0 \%$ & $\begin{array}{c}100 \\
\%\end{array}$ & $0 \%$ & $96 \%$ & .0 & 1.0 \\
\hline Casale 1985 & $\begin{array}{l}\mathrm{R} \text { aVL + S V3 >28 mm (males) } \\
>20 \mathrm{~mm} \text { (females) }\end{array}$ & $\begin{array}{c}6 \\
(3 \%)\end{array}$ & $\begin{array}{c}0.48 \\
(0.29-0.68)\end{array}$ & $0 \%$ & $97 \%$ & $0 \%$ & $96 \%$ & .0 & 1.0 \\
\hline Norman 1993 & $\begin{array}{l}\mathrm{R} \mathrm{aVL}+\mathrm{S} \mathrm{V} 3, \text { adj. for BMl/age } \\
>28 \mathrm{~mm} \text { (males), >20 mm } \\
\text { (females) }\end{array}$ & $\begin{array}{c}18 \\
(9 \%)\end{array}$ & $\begin{array}{c}0.65 \\
(0.42-0.87)\end{array}$ & $38 \%$ & $92 \%$ & $17 \%$ & $97 \%$ & 4.7 & 0.7 \\
\hline $\begin{array}{l}\text { Siegel } 1982, \\
\text { Malloy } 1992\end{array}$ & $\begin{array}{l}\text { Sum of }(R+S \text { or } Q) \text { in all } 12 \text { leads } \\
\geq 179 \mathrm{~mm}\end{array}$ & $\begin{array}{c}134 \\
(68 \%)\end{array}$ & $\begin{array}{c}0.60 \\
(0.42-0.78)\end{array}$ & $88 \%$ & $32 \%$ & $5 \%$ & $98 \%$ & 1.3 & 0.4 \\
\hline $\begin{array}{l}\text { Siegel } 1982, \\
\text { Ha } 2017\end{array}$ & $\begin{array}{l}\text { Sum of ( } \max \text { of } Q, R \text { or } S \text { ) in all } 12 \\
\text { leads } \geq 179 \mathrm{~mm}\end{array}$ & $\begin{array}{c}57 \\
(29 \%)\end{array}$ & $\begin{array}{c}0.74 \\
(0.56-0.92)\end{array}$ & $75 \%$ & $73 \%$ & $11 \%$ & $99 \%$ & 2.8 & 0.3 \\
\hline Peguero 2017 & $\begin{array}{l}\text { Max S any lead }+S \vee 4, \geq 28 \mathrm{~mm} \\
\text { (males), } \geq 23 \mathrm{~mm} \text { (females) }\end{array}$ & $\begin{array}{c}69 \\
(35 \%)\end{array}$ & $\begin{array}{c}0.64 \\
(0.44-0.84)\end{array}$ & $63 \%$ & $66 \%$ & $7 \%$ & $98 \%$ & 1.8 & 0.6 \\
\hline \multicolumn{10}{|l|}{ Non-voltage (1) } \\
\hline Carlsson 2006 & $\begin{array}{l}\text { QRS-duration, >114 ms (males), } \\
>97 \mathrm{~ms} \text { (females) }\end{array}$ & $\begin{array}{c}20 \\
(10 \%)\end{array}$ & $\begin{array}{c}0.45 \\
(0.26-0.63)\end{array}$ & $0 \%$ & $89 \%$ & $0 \%$ & $95 \%$ & .0 & 1.1 \\
\hline \multicolumn{10}{|c|}{ Voltage + non-voltage (4) } \\
\hline Romhilt 1968 & $\begin{array}{l}\text { Score } \geq 4 \text { : Voltage / STT V5-V6 / } \\
\text { LAA P in V1 / axis / QRS-dur }\end{array}$ & $\begin{array}{c}31 \\
(16 \%)\end{array}$ & $\begin{array}{c}0.74 \\
(0.54-0.95)\end{array}$ & $63 \%$ & $86 \%$ & $16 \%$ & $98 \%$ & 4.5 & 0.4 \\
\hline
\end{tabular}


Schillaci 1994

Molloy 1962,

Okin 1995

Molloy 1962

Molloy 1962

Ha 2017

\section{Mass equation/pred}

Rautaharju 1988

(female),

R V5, S V1, $\max ($ SIII, QIII),

Tneg(V6), Tpos(aVR), QRS-dur

R aVL + S V3) * QRS-dur, $\geq 2436$

12 leads * QRS-dur,

$17472 \mathrm{~mm} / \mathrm{ms}$

Sum of 12 leads (Vic) * QRS-dur

a) Rautaharju score not calculated for 15 athletes of other than Caucasian or Afro-American ethnicity. Current echocardiographic guidelines (Lang et al. 2015) define LVH in males as a LVM[BSA] >102 g/m². AUC, area under the curve; Sens/Spec, sensitivity/specificity; PPV/NPV, positive and negative predictive value; LR+/LR-, positive and negative likelihood ratio. Red colour indicates $95 \% \mathrm{Cl}$ not overlapping 0.50. 


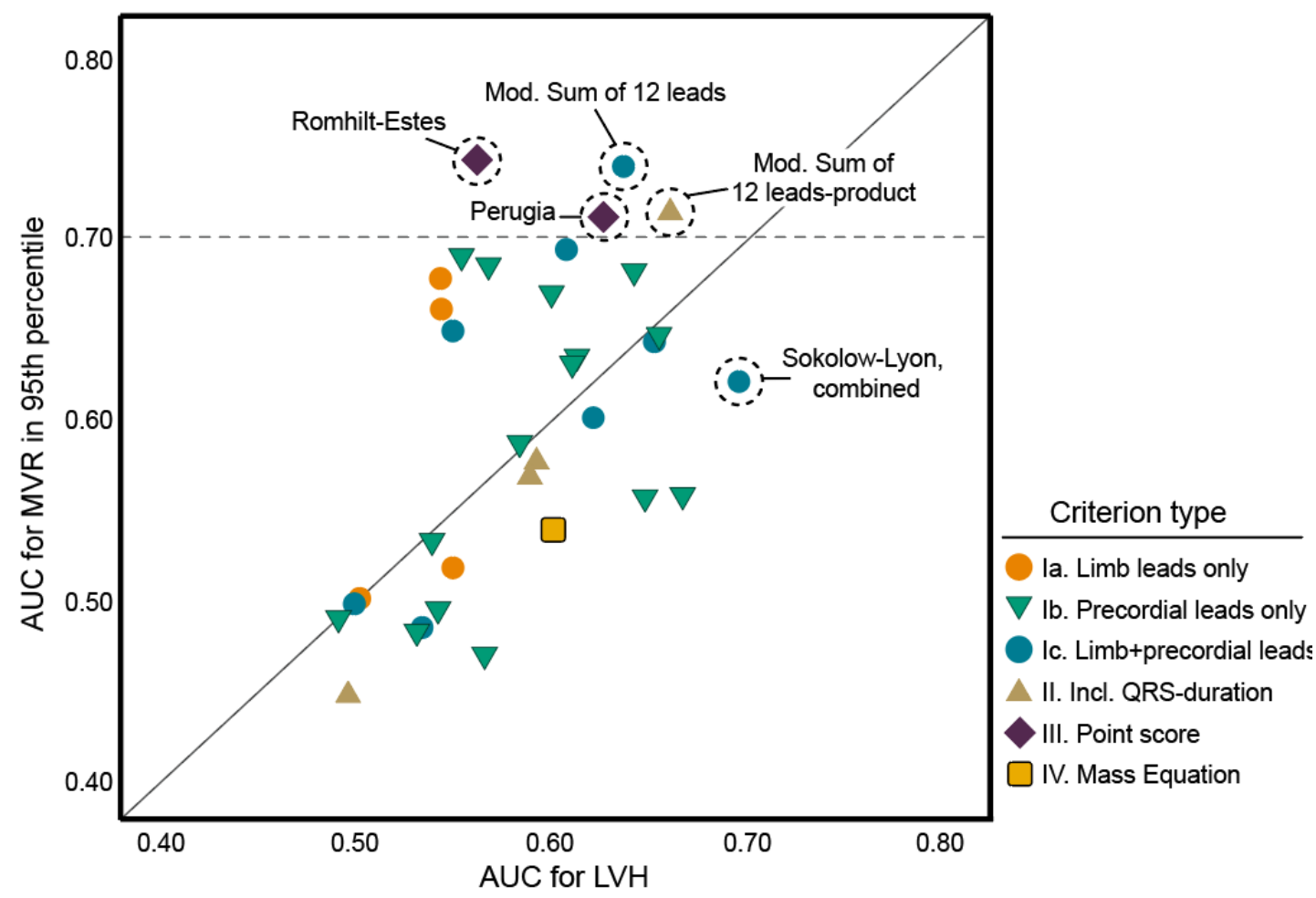

Supplemental Figure 4. Difference in area under the receiver operating curve (AUC) for each ECG criterion's ability to identify athletes with left ventricular hypertrophy $(\mathrm{LVH}, \mathrm{n}=11)$ and those with a mass to volume ratio $(\mathrm{M} / \mathrm{V})$ in the upper $95^{\text {th }}$ percentile $(n=8)$, respectively. 


\section{Supplementary Bibliography}

1. Gubner RS, Ungerlieder HE. Electrocardiographic criteria of left ventricular hypertrophy: factors determining the evolution of the electrocardiographic patterns in hypertrophy and bundle branch block. Arch Intern Med. 1943;72:196-209.

2. Sokolow M, Lyon TP. The ventricular complex in left ventricular hypertrophy as obtained by unipolar precordial and limb leads. Am Heart J. 1949;37:161-186.

3. Goldberger E. Unipolar Lead Electrocardiography and Vectorcardiography, Including Standard Leads, Augmented Unipolar Extremity Leads and Multiple Unipolar Precordial Leads, and a Section on Cardiac Arrhythmias. 2nd edition ed. Philadelphia, PA: Lea \& Febiger; 1949.

4. Schack JA, Rosenman RH, Katz LN. The aV limb leads in the diagnosis of ventricular strain. Am Heart J. 1950;40:696-705.

5. Romhilt DW, Bove KE, Norris RJ, et al. A critical appraisal of the electrocardiographic criteria for the diagnosis of left ventricular hypertrophy. Circulation. 1969;40:185-195.

6. Lewis T. Observations upon ventricular hypertrophy with special reference to preponderance of one or the other chamber. Heart. 1914;5:367-402.

7. Wilson FN, Johnston FD, Rosenbaum FF, et al. The precordial electrocardiogram. Am Heart J. 1944;27:19-85.

8. Mazzoleni A, Wolff R, Wolff L, Reiner L. Correlation between Component Cardiac Weights and Electrocardiographic Patterns in 185 Cases. Circulation. 1964;30:808-829.

9. Grant RP. Clinical Electrocardiography: The Spatial Vector Approach. New York, NY: McGraw-Hill Blakiston Division,; 1957.

10. McPhie J. Left ventricular hypertrophy: electrocardiographic diagnosis. Australas Ann Med. 1958;7:317-327.

11. Sharma S, Drezner JA, Baggish A, et al. International recommendations for electrocardiographic interpretation in athletes. Eur Heart J. 2018;39:1466-1480.

12. Wolff L. Electrocardiography: Fundamentals and Clinical Application. 2nd edition ed. Philadelphia, PA: WB Saunders; 1956.

13. Murphy ML, Thenabadu PN, de Soyza N, et al. Reevaluation of electrocardiographic criteria for left, right and combined cardiac ventricular hypertrophy. Am J Cardiol. 1984;53:1140-1147.

14. Holt DH, Spodick DH. The Rv6:Rv5 voltage ratio in left ventricular hypertrophy. Am Heart J. 1962;63:65-66.

15. Blackburn H. Classification of the electrocardiogram for population studies: Minnesota Code. J Electrocardiol. 1969;2:305-310.

16. Manning GW, Smiley JR. QRS-Voltage Criteria for Left Ventricular Hypertrophy in a Normal Male Population. Circulation. 1964;29:224-230.

17. Casale PN, Devereux RB, Kligfield P, et al. Electrocardiographic detection of left ventricular hypertrophy: development and prospective validation of improved criteria. J Am Coll Cardiol. 1985;6:572-580.

18. Norman JE, Jr., Levy D, Campbell G, Bailey JJ. Improved detection of echocardiographic left ventricular hypertrophy using a new electrocardiographic algorithm. J Am Coll Cardiol. 1993;21:1680-1686.

19. Molloy TJ, Okin PM, Devereux RB, Kligfield P. Electrocardiographic detection of left ventricular hypertrophy by the simple QRS voltage-duration product. J Am Coll Cardiol. 1992;20:1180-1186.

20. Siegel RJ, Roberts WC. Electrocardiographic observations in severe aortic valve stenosis: correlative necropsy study to clinical, hemodynamic,, and ECG variables demonstrating relation of 12-lead QRS amplitude to peak systolic transaortic pressure gradient. Am Heart J. 1982;103:210-221. 
21. Ha LD, Elbadawi A, Froelicher VF. Limited Relationship of Voltage Criteria for Electrocardiogram Left Ventricular Hypertrophy to Cardiovascular Mortality. Am J Med. 2018;131:101 e101-101 e108.

22. Peguero JG, Lo Presti S, Perez J, Issa O, Brenes JC, Tolentino A. Electrocardiographic Criteria for the Diagnosis of Left Ventricular Hypertrophy. J Am Coll Cardiol. 2017;69:1694-1703.

23. Carlsson MB, Tragardh E, Engblom $\mathrm{H}$, et al. Left ventricular mass by 12-lead electrocardiogram in healthy subjects: comparison to cardiac magnetic resonance imaging. J Electrocardiol. 2006;39:67-72.

24. Romhilt DW, Estes EH, Jr. A point-score system for the ECG diagnosis of left ventricular hypertrophy. Am Heart J. 1968;75:752-758.

25. Schillaci G, Verdecchia $P$, Borgioni $C$, et al. Improved electrocardiographic diagnosis of left ventricular hypertrophy. Am J Cardiol. 1994;74:714-719.

26. Rautaharju PM, LaCroix AZ, Savage DD, et al. Electrocardiographic estimate of left ventricular mass versus radiographic cardiac size and the risk of cardiovascular disease mortality in the epidemiologic follow-up study of the First National Health and Nutrition Examination Survey. Am J Cardiol. 1988;62:59-66. 